\title{
ER stress-mediated BK dysfunction in the DRG underlies pain in a model of multiple sclerosis
}

Muhammad Saad Yousuf ${ }^{a}$, Samira Samtleben $^{\mathrm{b}}$, Shawn M. Lamothe ${ }^{\mathrm{c}}$, Timothy Friedman ${ }^{\mathrm{a}}$, Ana Catuneanu $^{\mathrm{c}}$, Kevin Thorburn ${ }^{\mathrm{c}}$, Mansi Desai ${ }^{\mathrm{a}}$, Gustavo Tenorio ${ }^{\mathrm{f}}$, Geert J. Schenk ${ }^{\mathrm{d}}$, Klaus Ballanyi ${ }^{\mathrm{e}}$, Harley T. Kurata ${ }^{\mathrm{a}, \mathrm{c}}$, Thomas Simmen ${ }^{\mathrm{b}}$ and Bradley J. Kerr ${ }^{\mathrm{a}, \mathrm{c}, \mathrm{f}_{*}}$

${ }^{a}$ Neuroscience and Mental Health Institute, University of Alberta, Edmonton, AB, Canada, T6G 2E1

${ }^{\mathrm{b}}$ Department of Cell Biology, University of Alberta, AB, Canada T6G 2E1

${ }^{\mathrm{c}}$ Department of Pharmacology, University of Alberta, Edmonton, AB, Canada, T6E 2H7

${ }^{\mathrm{d}}$ Department of Anatomy and Neurosciences, Neuroscience Amsterdam, Amsterdam UMC, VU

University Medical Center, VUmc MS Center Amsterdam, Amsterdam, The Netherlands

${ }^{\mathrm{e}}$ Department of Physiology, University of Alberta, AB, Canada T6G 2E1

${ }^{\mathrm{f}}$ Department of Anesthesiology and Pain Medicine, University of Alberta,

Edmonton, AB, Canada, T6G 2G3

Keywords: DRG, ER Stress, Pain, MS, EAE, BK channel

Number of words Abstract: 182

Number of words Discussion: 1496

Number of Figures: 11 (plus 2 extended figures)

Number of Tables: 2

Running title: ER stress contributes to pain in EAE

\section{Acknowledgements}

We would like to thank Drs. Simonetta Sipione, Christine Webber, and Jason Plemel (University of Alberta) for graciously sharing select equipment and software. Funding for this project was provided by operating grants from CIHR, the University of Alberta Hospital Foundation, the MS Society of Canada (MSSC), NSERC, Canada Foundation for Innovation (CFI), and Alberta Advanced Technology and Education. MSY was supported by the Alexander Graham Bell Canada Graduate Scholarship from NSERC. SS was supported by a Campus Alberta Neuroscience postdoctoral fellowship. The authors would like to thank the donors, their families, and the Netherlands brain bank.

\section{Conflict of Interest}

The authors declare no conflict of interest.

\section{*Corresponding Author:}

Dr. Bradley J. Kerr

Dept. of Anesthesiology and Pain Medicine

Clinical Sciences Building, 2-150

University of Alberta

Edmonton, Alberta

Canada, T6G 2G3

bradley.kerr@ualberta.ca 


\section{ABSTRACT}

Neuropathic pain is a common symptom of multiple sclerosis (MS) and current treatment options are ineffective. In this study, we investigated whether endoplasmic reticulum (ER) stress in dorsal root ganglia (DRG) contributes to pain hypersensitivity in the experimental autoimmune encephalomyelitis (EAE) mouse model of MS. Inflammatory cells and increased levels of ER stress markers are evident in post-mortem DRGs from MS patients. Similarly, we observed ER stress in the DRG of mice with EAE and relieving ER stress with a chemical chaperone, 4phenylbutyric acid (4-PBA), reduced pain hypersensitivity. In vitro, 4-PBA and the selective PERK inhibitor, AMG44, normalize cytosolic $\mathrm{Ca}^{2+}$ transients in putative DRG nociceptors. We went to assess disease-mediated changes in the functional properties of $\mathrm{Ca}^{2+}$-sensitive BK-type $\mathrm{K}^{+}$channels in DRG neurons. We found that the conductance-voltage $(\mathrm{GV})$ relationship of BK channels was shifted to a more positive voltage, together with a more depolarized resting membrane potential in EAE cells. Our results suggest that ER stress in sensory neurons of MS patients and mice with EAE is a source of pain and that ER stress modulators can effectively counteract this phenotype. 


\section{INTRODUCTION}

Multiple sclerosis (MS) is a chronic, neurodegenerative disorder characterized by immune activation and loss of myelin in the central nervous system (CNS). Among the many sensory abnormalities associated with MS, pain is common and often debilitating. Pain is experienced by one third to a half of the population with MS at some point during their disease course and a significant percentage are diagnosed with neuropathic pain $(1,2)$. Current pharmacological approaches to alleviate this pain have been largely ineffective with low patient confidence in prevailing treatment approaches (3). To investigate the pathophysiology of pain in MS, we employed a commonly used animal model, experimental autoimmune encephalomyelitis (EAE).

Neuropathic pain is thought to arise from increased excitability of neurons along the pain axis, comprising sensory neurons in the peripheral dorsal root and trigeminal ganglia and the integrative central processes of the spinal cord and the brain (4-6). The role of the CNS as a modulator of pain in MS/EAE has been widely studied (7). However, only a handful of studies to date has investigated the contribution of the peripheral branch of the somatosensory nervous system to pain pathophysiology in EAE and MS (8-14).

In response to MS/EAE, the central projections of the DRG neuronal somata may sustain indirect injury through chronic neuroinflammatory processes occurring in the CNS. These injuries at the spinal terminal may evoke a retrograde stress response in the cell bodies of the DRG. When cells are subject to chronic stressors, such as prolonged inflammation and cytoskeletal disruption, they may undergo endoplasmic reticulum (ER) stress. The ER is an important organelle required for lipid biosynthesis, calcium ion $\left(\mathrm{Ca}^{2+}\right)$ storage and protein folding and processing (15). Stress can impair protein folding thus triggering a cascade of events that are collectively known as the unfolded protein response (UPR) $(16,17)$. 
The ER-based signalling mechanism initially functions to mitigate cellular damage.

Activation of the UPR is mediated by three ER stress sensor proteins, IRE1, PERK, and ATF6 (15). Signaling initiated through these three independent pathways promotes cell survival by ultimately reducing misfolded protein levels both via reducing mRNA translation and via enhancing the ER's folding capacity. If the stressor is particularly severe or prolonged however, the UPR can drive the cell into an apoptotic program of regulated cell death $(15,17)$. Emerging evidence is now demonstrating that ER stress may also be a significant factor for developing pain hypersensitivity in various animal models across a variety of cell types (18-25). In this study, we investigated whether ER stress in DRG neurons contributes to the well characterised pain hypersensitivity that occurs in the EAE model and by extension in MS $(7,26)$. 


\section{MATERIALS AND METHODS}

\section{Human Tissue}

Human tissue was obtained from the Netherlands Brain Bank (NBB; http://www.brainbank.nl). Subjects or their next of kin provided written informed consent for the use of their tissue and clinical information for research purposes to the NBB. All MS individuals $(n=9)$ experienced the progressive phase of the disease and presented evidence of chronic pain such as trigeminal neuralgia, migraine, extremity pain, and back pain. The average disease duration was $21.0 \pm 4.61$ years. Average age at death was $78.6 \pm 4.32$ years for the non-demented controls $(n=7)$ and 59.7 \pm 4.04 years for individuals with MS. The majority of the donors elected to be euthanized with a combination of barbiturates (thiopental, pentobarbital) and muscle relaxant (Rocuronium bromide). Only female human tissue was examined. Patient demographics are further summarized in Table 1-1.

Snap frozen human DRGs were sectioned onto superfrost plus glass slides (VWR International, Leuven, Belgium) at $10 \mu \mathrm{m}$ thickness. Ten $10 \mu \mathrm{m}$ thick sections were harvested for RNA and protein analysis. Tissue was lysed in $600 \mu 1$ of Buffer RLT (Qiagen, 79216) with $\beta$ mercaptoethanol (Sigma, M3148, 10 $\mu 1 / \mathrm{ml}$ of Buffer RLT) using a 2 ml Potter-Elvehjem homogenizer. The homogenate was then centrifuged at full speed for $2 \mathrm{~min}$ in QIAshredder column (Qiagen, 79656). RNA was extracted from the flow-through using the RNeasy Mini Kit (Qiagen, 74104) according to manufacturer's instructions. RNA was quantified using a Nanodrop 2000. Reverse transcription and PCR analysis was performed as described later.

The flow-through after RNeasy spin column centrifugation step was stored at $4^{\circ} \mathrm{C}$ for protein extraction. The protein was precipitated using ice-cold acetone $(500 \mu 1$ sample $+1500 \mu 1$ acetone). The acetone laden sample was store at $-20^{\circ} \mathrm{C}$ for 2 hours and then centrifuged at 
$15,000 \mathrm{~g}$ for $10 \mathrm{~min}$ at $4^{\circ} \mathrm{C}$. The supernatant was discarded and the pellet was redissolved in $100 \mu 1$ of 5\% SDS. Protein was quantified using the DC Protein Assay (BioRad, 5000112). Western blots using $10 \mu \mathrm{g}$ of protein were performed as described below.

Immunohistochemical analysis of human DRG sections were performed similar to previously described $(10,27)$. In brief, slides were fixed in acetone for $10 \mathrm{~min}$, followed by three 5-min gentle PBS washes, after which the slides were air dried in a fumehood for $30 \mathrm{~min}$. The sections were blocked at room temperature with $10 \%$ NGS in PBS. Primary antibody dissolved in antibody solution (1\% BSA and $0.2 \%$ NGS in PBS) was placed over the DRG sections overnight. The slides were then washed in PBS $(3 \mathrm{x}-5 \mathrm{~min}$ each) followed by 1 hour incubation in secondary antibody (1:200) dissolved in antibody solution. Another set of washes in PBS (3x-5 min each) were performed and then the slides were mounted using Vectashield with DAPI (Vector Labs, H-1200).

The use of tissue and access to medical records was approved from the Ethics Committee of the VU University Medical Center, Amsterdam, The Netherlands.

\section{EAE induction and behavioural assessment}

As previously described (9), experimental autoimmune encephalomyelitis (EAE) was induced in

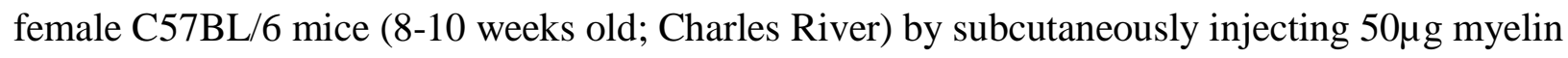
oligodendrocyte glycoprotein $\left(\mathrm{MOG}_{35-55}\right.$; Stanford University Peptide Synthesis Facility) emulsified in complete Freund's adjuvant (CFA; $1.5 \mathrm{mg} / \mathrm{ml})$ followed by inoculations with 300ng of pertussis toxin, Bordatella pertussis, (List Biological Labs) on the day of induction and 48 hours later. All animal experiments were performed according to Canadian Council on Animal 
Care's Guidelines and Policies with approval from University of Alberta Health Sciences Animal Care and Use Committee.

Mechanical hypersensitivity, facial sensitivity, and gross locomotor ability were assessed as previously described $(8,9,28)$. Data was compared to the baseline threshold of each individual mouse in order to control for individual differences and experimenter variability.

\section{4-PBA administration in vivo}

4-PBA (200mg/kg; Tocris, 2682) was completely dissolved in 1X sterile PBS and injected intraperitoneally $(n=6)$ daily, beginning at disease onset until day 7-10 post-onset. PBS was administered as a vehicle control $(n=5)$. Von Frey testing was performed one-hour after injection on the day of disease onset. Facial sensitivity was assessed using the air puff assay one-hour after the final injection 7-10 days post onset.

\section{Immunohistochemistry}

The mouse tissue was fixed with $4 \%$ paraformaldehyde (PFA) in $0.1 \mathrm{M}$ phosphate buffer (PB) overnight at $4{ }^{\circ} \mathrm{C}$ followed by two $30 \%$ sucrose washes, each overnight at $4{ }^{\circ} \mathrm{C}$. After removing excess sucrose, the tissue was embedded in Tissue-Tek OCT (Sakura Finetek, 4583). DRGs were cryosectioned with $10 \mu \mathrm{m}$ thickness while the spinal cords were sectioned at $20 \mu \mathrm{m}$ onto glass slides. The remaining staining protocol was identical to a previously established protocol (10).

\section{Western blotting}

Protein lysates were diluted in RIPA (25mM Tris, $150 \mathrm{mM} \mathrm{NaCl}, 0.1 \%$ SDS, $0.5 \% \mathrm{Na}$ deoxycholate, 1\% NP-40) with protease (cOmplete EDTA-free, Roche, 04693159001) and 
phosphatase inhibitors (PhosSTOP, Roche, 04906837001) and 5X sample buffer was added.

Directly before loading onto $10 \%$ SDS-PAGE gels, samples were boiled at $100^{\circ} \mathrm{C}$ for $10 \mathrm{~min}$.

Gels were run at $150 \mathrm{~V}$ for $60 \mathrm{~min}$ and transferred onto nitrocellulose membranes with $400 \mathrm{~mA}$ over $120 \mathrm{~min}$.

Membranes were stained with REVERT Total Protein Stain (Licor) according to manufacturer's instructions and then blocked in 2\% BSA in 1X DPBS for 1 hour at room temperature followed by overnight incubation at $4{ }^{\circ} \mathrm{C}$ with a primary antibody dissolved in blocking solution. Membranes were then washed 3 times ( 3 minutes each) in TBS-T and incubated in $2 \%$ milk in TBS-T with Alexa Fluor coupled secondary antibodies for $1 \mathrm{~h}$ at room temperature. After another wash step, membranes were scanned using an Odyssey infrared imager (Licor).

Western blots using human tissue were performed as previously described (10). Stain free gels (BioRad, 456-8093, 4-20\%) were transferred onto low-fluorescence PVDF blots (BioRad, 1704274) using the Trans-Blot Turbo transfer system (BioRad). Total protein was quantified using Stain-Free technology (BioRad) according to manufacturer's instructions. Blots were imaged with BioRad ChemiDoc XRS+ system and quantified using Image Lab 6.0 (BioRad) with total protein as loading control. Antibodies are summarized in Table 2-2.

\section{Quantitative real-time PCR}

Reverse transcription and PCR analyses were performed as previously described (10). Reverse transcription on human samples was performed using 160ng of total RNA. PCRs were performed on StepOne Plus thermocycler using Rpl5 (mouse) or RPLPO (human) as housekeeping genes. Primers used in this study were obtained from Qiagen: Rpl5 (PPM25102A), Xbpl 
(PPM05627A), Ddit3 (PPM03736A), Hspa5 (PPM03586B), Kcnmb1 (PPM04055A), Kcnmb4 (PPM36505B), Kcnmal (PPM04054G), RPLP0 (PPH21138F), C3AR1 (PPH02514A), C5AR1 (PPH06063F), CD3E (PPH01486B), CD4 (PPH01629C), XBP1 (PPH02850A), KCNMA1 (PPH01663A), KCNMB1 (PPH01417A), KCNMB4 (PPH17370A).

\section{Dissociated DRG cultures}

Dissociated DRG cultures for calcium imaging were prepared from freshly excised DRGs according to our previously published protocol (see "Dissociated dorsal root ganglia cultures", 11) with STEMzyme I (2mg/ml; Worthington, LS004106) replacing collagenase IV. For electrophysiology experiments, DRG neurons were dissociated with a mix of STEMzyme I (1mg/ml) and trypsin (0.5mg/ml; HyClone, SV3003101).

In vitro application of 4-PBA was prepared as a stock solution of 100mM in Hank's balanced salt solution (HBSS) (Hyclone, SH30030.02). Stock solution of AMG44 (Tocris, 5517, $3 \mathrm{mM}$ ) was prepared in sterile 60\% dimethyl sulfoxide (DMSO; Sigma, D2650). Dissociated cells received diluted 4-PBA (final concentration: $10 \mathrm{mM}$ ) and AMG44 (final concentration: $5 \mu \mathrm{M}$ ) treatment one-hour after plating in cell media (DMEM/F12 [Gibco, 10565018], 1\% N 2 [Gibco, 17502048], 1\% penicillin/streptomycin [Gibco, 1570063]). Vehicle treatment in each experiment consisted of equal volume of either HBSS or DMSO (final concentration: $0.1 \%$ ). Cells were incubated in their respective treatment conditions for 20-24 hours prior to $\mathrm{Ca}^{2+}$ imaging and electrophysiology.

Gene knockdown experiments were performed with HiPerfect transfection system (Qiagen, 301705) using Flexitube siRNA (Qiagen; XBP1: GS22433, Ddit3: GS13198, AllStars Negative Control siRNA: 1027284). The Flexitube siRNA contains a cocktail of multiple siRNA 
targeting multiple regions of the mRNA. The siRNA cocktail was prepared according to manufacturer's instructions. The final total siRNA concentration was $0.04 \mu \mathrm{M}$ (4 individual siRNAs, each at $0.01 \mu \mathrm{M}) .100 \mu \mathrm{l}$ of siRNA mixture was added to cells (100 $\mu 1$ droplet) one hour after plating them onto glass coverslips. The cells were incubated for 10 min at $37^{\circ} \mathrm{C}$ and then topped up to $1 \mathrm{ml}$ in cell media followed by incubation for $20-24$ hours prior to $\mathrm{Ca}^{2+}$ imaging.

\section{Live cell $\mathrm{Ca}^{2+}$ imaging in DRG neurons}

Confocal imaging of cytosolic $\mathrm{Ca}^{2+}$ transients was performed as previously described (11) with the addition of caffeine (Sigma, C0750) dissolved in superfusate (in mM) $(120 \mathrm{NaCl}, 3 \mathrm{KCl}, 1$ $\mathrm{CaCl}_{2}, 2 \mathrm{MgSO}_{4}, 20$ glucose). After 5 min of equilibration in the optical recording chamber with superfusate, administered with a peristaltic pump at $4 \mathrm{ml} / \mathrm{min}$, the imaging paradigm was as follows: 30s superfusate perfusion (baseline), 30s caffeine (20mM), 4 min superfusate perfusion, 5 min washout period, 30s superfusate perfusion (baseline), $30 \mathrm{~s} \mathrm{KCl}(30 \mathrm{mM}), 4 \mathrm{~min}$ superfusate perfusion. The imaging data were analyzed using Olympus FV10-ASW software with the first 30s as baseline for each caffeine and $\mathrm{KCl}$ application. The remaining recording was divided by the baseline to obtain a ratio of change in fluorescence (Fluo-4 F/F). These data were further normalized to an internal control of the particular experiment (e.g. $\mathrm{Ca}^{2+}$ transients were normalized to CFA in the AMG44 experiment, EAE vehicle in the 4-PBA and siRNA experiments). As such, the average amplitude of all cells in the control group was used to normalize the $\mathrm{Ca}^{2+}$ response of the treated group. Once the imaging was completed, the $15 \mathrm{~mm}$ diameter coverslips were placed in 12 well plate with $600 \mu 1$ of Buffer RLT (Qiagen). These plates were stored at $-80^{\circ} \mathrm{C}$ until RNA extraction. Total RNA was extracted from individual coverslips using RNeasy Micro Kit (Qiagen, 74004) according to manufacturer's instructions. 


\section{Perforated patch whole-cell recordings}

Solutions: The extracellular bath solution contained (in $\mathrm{mM}$ ): $135 \mathrm{NMDG}, 5 \mathrm{KCl}, 2.8$ $\mathrm{NaCH}_{3} \mathrm{CO}_{2}, 1 \mathrm{CaCl}_{2}, 1 \mathrm{MgCl}_{2}, 10 \mathrm{HEPES}$ and was adjusted to $\mathrm{pH} 7.4$ with $\mathrm{HCl}$. The intracellular (pipette) solution contained (in mM): $135 \mathrm{KCl}, 5$ EGTA, 10 HEPES and was adjusted to $\mathrm{pH} 7.2$ with $\mathrm{KOH}$. Amphotericin B was used to perforate the patch and solutions were made fresh before use. $6 \mathrm{mg}$ amphotericin powder (Sigma) was added to 100 $\mu \mathrm{l}$ of DMSO and solubilized in a $1.5 \mathrm{ml}$ centrifuge tube. From the $60 \mathrm{mg} / \mathrm{ml}$ stock solution, $20 \mu \mathrm{l}$ was added to $5 \mathrm{ml}$ of pipette solution for a final concentration of $240 \mu \mathrm{g} / \mathrm{ml}$. Paxilline (Tocris), used to inhibit BK channels, was dissolved in EtOH at a stock concentration of $1 \mathrm{mM}$. Paxilline was added to $40 \mathrm{ml}$ of bath solution for a desired working concentration of $1 \mu \mathrm{M}$ and perfused into the chamber when appropriate.

Data acquisition and analysis: Prior to experiments, $5 \mu 1$ of Alexa488-conjugated IB4antibody (Invitrogen, $1 \mathrm{mg} / \mathrm{ml}$ ) was added for 10 minutes then removed, to differentiate between IB4+ and IB4- DRG neurons. Glass coverslips containing cells were removed from the incubator $\left(37^{\circ} \mathrm{C}\right)$ and placed in a superfusion chamber containing the bath solution at ambient temperature $\left(22-23^{\circ} \mathrm{C}\right) . \mathrm{IB} 4+$ neurons were observed with epifluorescence illumination. Patch pipettes were manufactured from soda lime glass (Fisher), using a Sutter P-97 puller (Sutter Instrument). When filled with internal solution, patch pipettes had a tip resistance of 2-4 $\mathrm{M} \Omega$. After formation of a gigaohm seal between pipette tip and cell, currents were recorded through amphotericin Binduced pores. Whole-cell perforated patch clamp recordings were acquired and analyzed using a Digidata 1440 digitizer, an Axopatch 200B amplifier and Clampex 10 software (Molecular Devices). Recordings were sampled at $10 \mathrm{kHz}$ and filtered at $5 \mathrm{kHz}$, with manual capacitance 
compensation and series resistance compensation at (80\%). In voltage-clamp mode, total IK was measured by stepping between -130 and $200 \mathrm{mV}(100 \mathrm{~ms}$ in $10 \mathrm{mV}$ increments) from a $-100 \mathrm{mV}$ holding potential followed by a $100 \mathrm{~ms}$ tail current voltage at $-30 \mathrm{mV}$. Bath solution containing $1 \mu \mathrm{M}$ paxilline was perfused in the chamber for 2 minutes to inhibit BK channels. During perfusion, IK was recorded with a $+60 \mathrm{mV}$ depolarizing pulse for $150 \mathrm{~ms}$ with $5 \mathrm{~s}$ interpulses from a $-80 \mathrm{mV}$ holding voltage to observe paxilline-induced current reduction. To isolate $\mathrm{BK}$ currents, currents were subtracted immediately before and after application of $1 \mu \mathrm{M}$ Paxilline from paxilline-sensitive (IB4+) DRG neurons. BK channel conductance-voltage (G/V) relationships were generated by analyzing the tail current amplitudes and fit with a Boltzmann function. BK channel current density was measured by dividing the current amplitude (pA) at +60 mV by cell capacitance $(\mathrm{pF})$. Resting membrane potentials were recorded using current clamp mode from IB4+ DRG neurons using perforated-patch clamp. Vehicle treatment with HBSS (vehicle for 4-PBA) and 0.01\% DMSO (vehicle for AMG44) resulted in identical recordings and hence, two vehicle treatments were collapsed into a single group. DRG neurons from EAE animals were obtained at disease onset and the chronic time point (7-10 days post onset).

\section{Experimental Design and Statistical Analysis}

Statistical analyses were performed using GraphPad Prism 6 with appropriate statistical tests.

Detailed statistical analyses have been mentioned in the Results section. Animals were assigned to each experimental group randomly. Western blot and PCR data were log-transformed prior to statistical testing in order to ensure the data fit the homogeneity of variance assumptions for each statistical test. The data presented in the figures is back-transformed onto a linear scale for the 
ease of the reader. Statistical annotations represent output of tests performed on log-transformed

data. Significance was set at $p<0.05$. Graphics were generated using Biorender.com.

\section{Data availability}

The data that support the findings of this study are available from the corresponding author, upon reasonable request. 


\section{RESULTS}

\section{Inflammation and ER stress in the post-mortem MS DRG}

Although MS is classically identified as a CNS targeted disease, we sought to investigate whether sensory neurons residing in the DRG of the PNS are also affected by the disease. We first examined post-mortem DRG tissue from MS patients for activation of innate and adaptive immune responses. At the transcript level, the complement component 3a receptor 1 (C3AR1), and complement component 5a receptor 1 (C5AR1), were upregulated in MS tissue compared to non-demented controls $\left(\mathrm{t}_{\mathrm{C} 3 \mathrm{aR} 1}(10)=2.019, \mathrm{p}=0.0711 ; \mathrm{t}_{\mathrm{C} 5 \mathrm{aR} 1}(11)=3.928, \mathrm{p}=0.0024\right.$, unpaired $\mathrm{t}$-test $)$

(Fig. 1A, B). We also noted a significant increase in the T-cell marker transcripts, CD3 and CD4, further suggesting that the adaptive immune response was engaged in the DRG during the disease $\left(\mathrm{t}_{\mathrm{CD} 3 \mathrm{E}}(11)=4.358, \mathrm{p}=0.0011 ; \mathrm{t}_{\mathrm{CD} 4}(11)=3.466, \mathrm{p}=0.0053\right.$, unpaired $\mathrm{t}$-test $)$ (Fig. 1C, D). Similar activation at the level of the DRG in the EAE animal model has been previously described by our group (10). Further analysis revealed a significant increase in specific markers of ER stress at the level of the DRG in MS. XPB1 mRNA as well as BiP and XBP1 protein levels were increased in MS tissue suggesting that the DRG in MS undergoes ER stress (PCR: $\mathrm{t}_{\mathrm{XBP} 1}(9.119)=3.482, \mathrm{p}=0.0068$, unpaired t-test with Welch's correction; WB: $\mathrm{t}_{\mathrm{BiP}}(14)=2.579$, $\mathrm{p}=0.0219 ; \mathrm{t}_{\mathrm{XBP} 1}(14)=2.290, \mathrm{p}=0.0253$, unpaired $\mathrm{t}$-test $)($ Fig. 1E-H).

We next performed immunofluorescence experiments to identify the source of inflammation and ER stress. C5aR1 (CD88), and CD3 immunopositive immune cells were increased in MS samples as compared to non-demented controls (Fig. 1I). Furthermore, BiP expression was observed to be increased in MS DRGs and largely localized to sensory neurons (Fig. 1I). This data indicates that peripheral sensory neurons in the DRG of MS patients are subjected to immune activation and ER stress. 
Figure 1
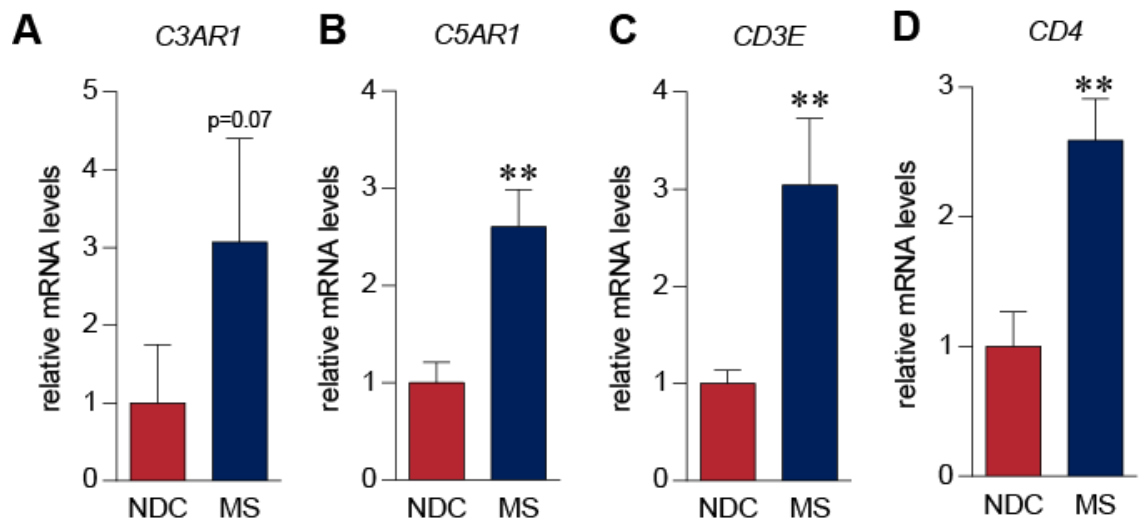

\section{E}
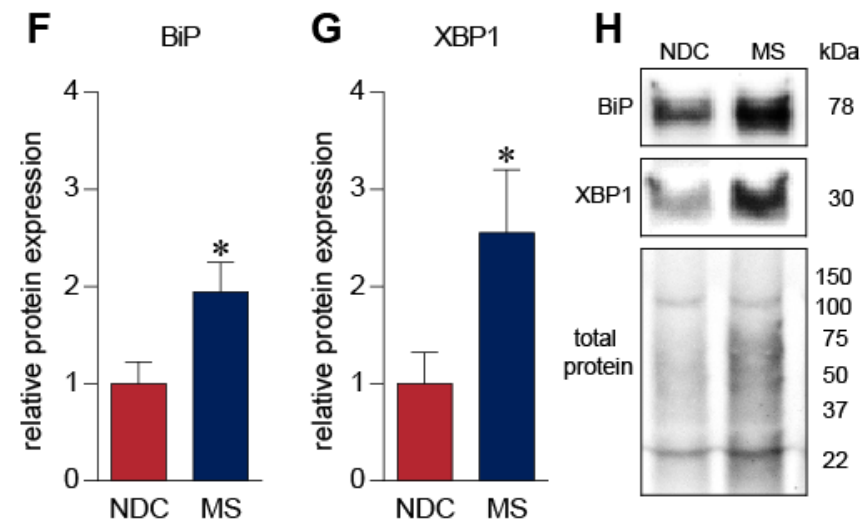

I
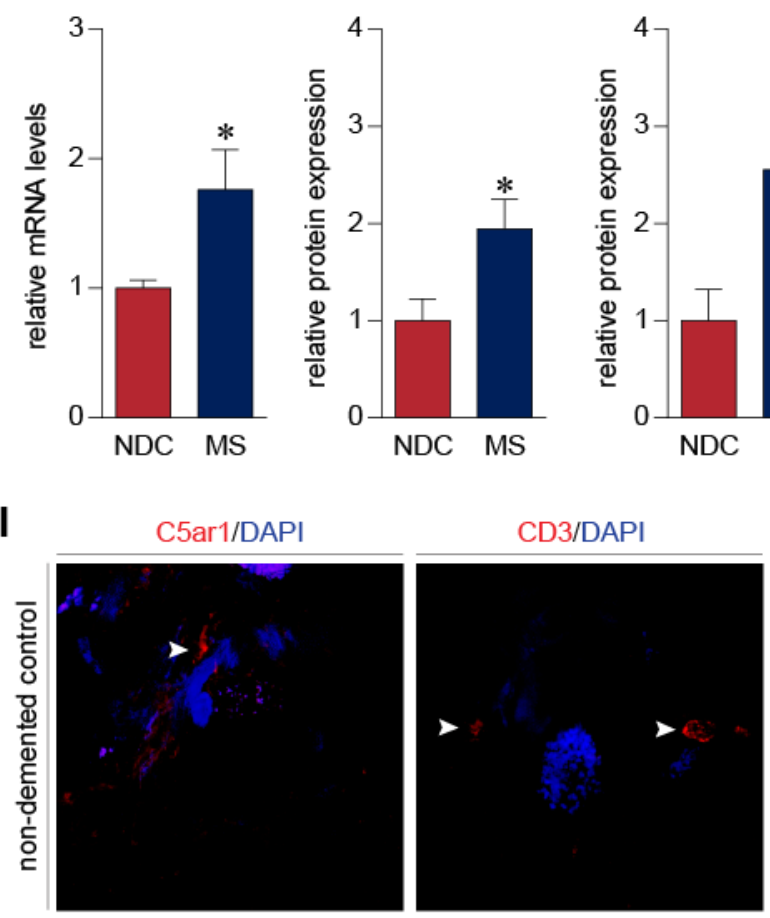

BiP/DAPI
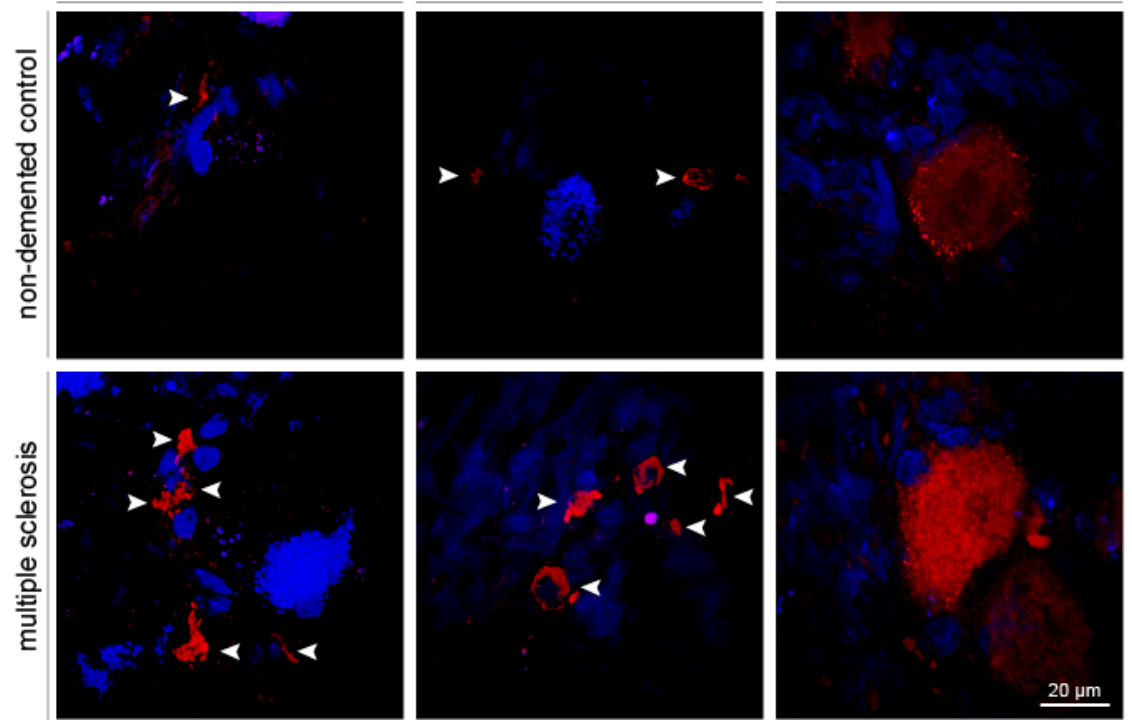
Figure 1. Human DRGs undergo inflammation, immune activation, and ER stress in MS. (A-B) PCR analysis of post-mortem human DRGs revealed that the complement component C3a receptor 1 (C3AR1) and component $\mathrm{C} 5$ a receptor 1 (C5AR1) genes are upregulated in chronic MS tissue ( $n=8)$ as compared to DRGs obtained from non-demented controls (NDC; $n=5)$. $(C$, D) Similarly, we observed an increase in T-cell enriched CD3E and CD4 mRNA expression in MS tissue as compared to NDC. (E) mRNA transcripts of X-box binding protein 1 (XBP1) were also found to be elevated in MS DRG tissue with respect to levels in NDC samples. (F-H) Western blotting revealed an increase in binding immunoglobulin protein (BiP) and XBP1 protein levels in MS DRGs $(n=9)$ compared to NDCs $(n=7)$. $(H)$ Immunofluorescence experiments localized expression of C5ar1 and CD3 in immune cells however BiP expression was restricted to be elevated in neurons. Bars indicate mean \pm standard error of mean (SEM). * $\mathrm{p}<0.05, * * \mathrm{p}<0.01$, unpaired t-test.

\section{EAE mice develop pain hypersensitivity}

We next generated EAE in female C57BL/6 mice using myelin oligodendrocyte glycoprotein $\left(\mathrm{MOG}_{35-55}\right)$. The median day for the onset of EAE clinical signs was day 10 post immunization (Fig. 2A, B). Behavioural testing was carried out at this time-point. In our model of EAE, mice exhibit a characteristic mechanical hypersensitivity at disease onset that is reflected by a reduced threshold to von Frey hair stimulation as expressed as a percentage of their own baseline threshold $\left(\mathrm{F}_{\text {interaction }}(1,11)=28.43, \mathrm{p}=0.0002, \mathrm{~F}_{\text {timepoint }}(1,11)=29.40, \mathrm{p}=0.0002\right.$, $\mathrm{F}_{\text {disease }}(1,11)=7.932, \mathrm{p}=0.0168, \mathrm{~F}_{\text {subjects }}(11,11)=3.584, \mathrm{p}=0.0224, \mathrm{RM}$ two-way ANOVA) (Fig. 2C). At this time point, we do not observe any significant change in locomotor abilities (time spent on the rotarod $)\left(F_{\text {interaction }}(1,8)=1.090, p=0.3269, F_{\text {timepoint }}(1,8)=0.7348, p=0.4163\right.$, $\mathrm{F}_{\text {disease }}(1,8)=0.6992, \mathrm{p}=0.4273, \mathrm{~F}_{\text {subjects }}(8,8)=1.035, \mathrm{p}=0.4811, \mathrm{RM}$ two-way ANOVA) (Fig. 2D). Hence, mechanical hypersensitivity observed in EAE mice at disease onset was not confounded by paralysis or lack of motor coordination. 
Figure 2

A

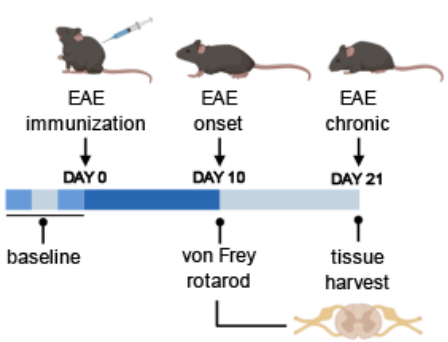

B

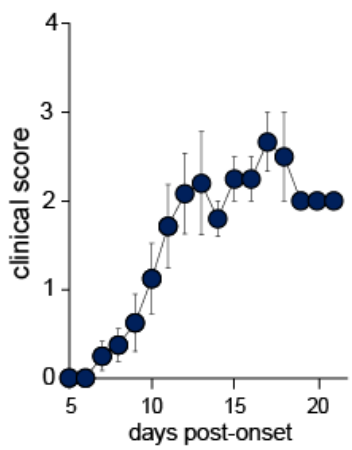

C

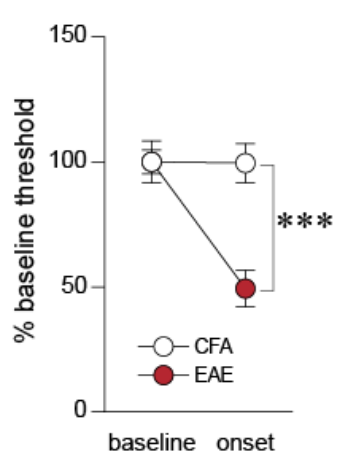

D rotarod

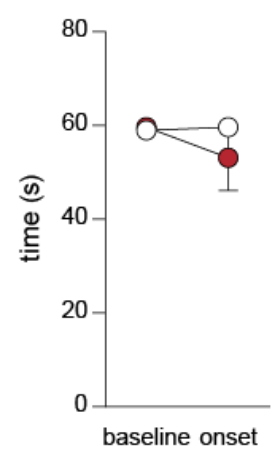

E

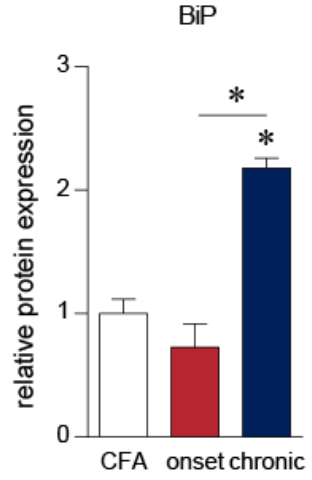

I

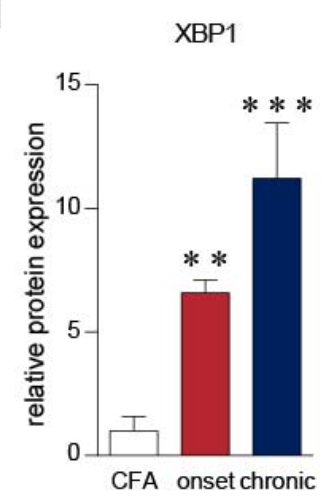

$\mathbf{L}$

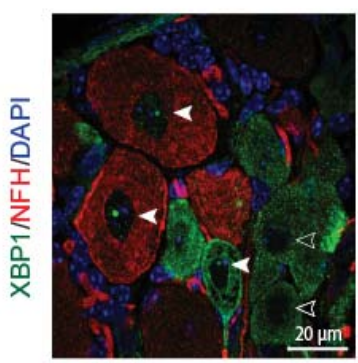

F

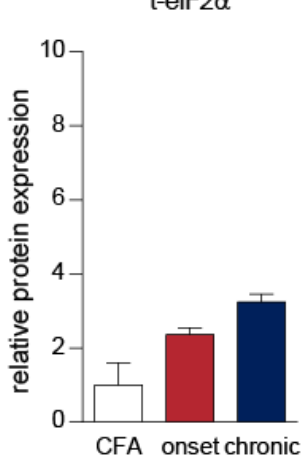

J

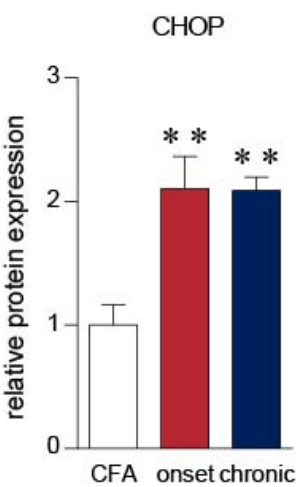

G

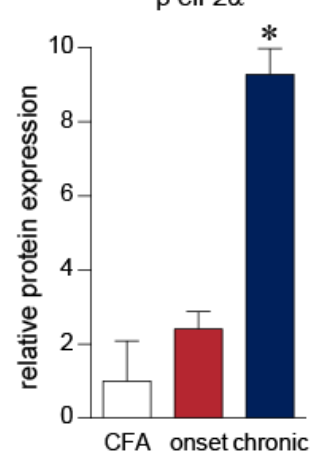

K

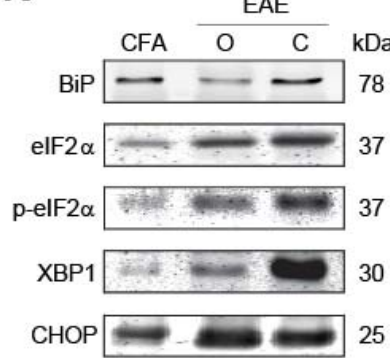

H p-elF $2 \alpha /$ t-elF $2 \alpha$
M

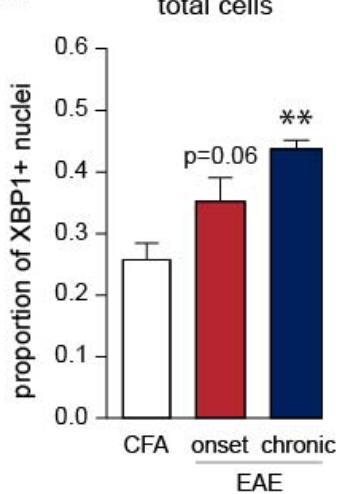

$\mathbf{N}$

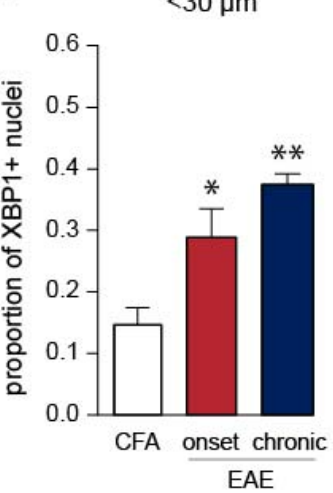

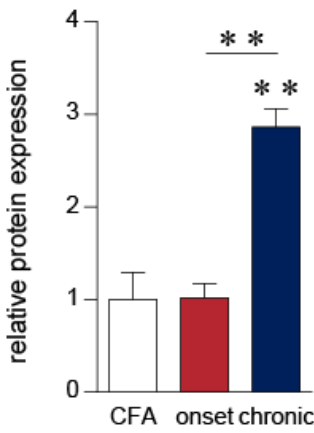

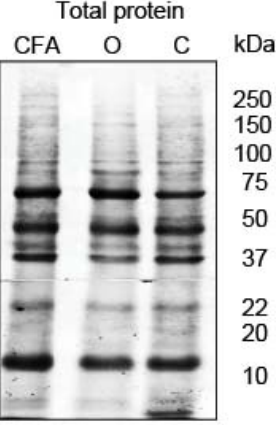

0

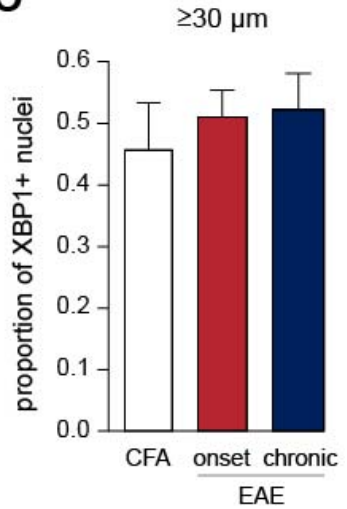


Figure 2. ER stress-associated proteins are dysregulated in the DRG of EAE mice. (A, B) 810 week old female mice were immunized against myelin oligodendrocyte glycoprotein $\left(\mathrm{MOG}_{35}\right.$ ${ }_{55}$ ) to induce EAE. Behavioural analyses were performed at the onset of EAE signs. Mice developed initial clinical symptoms (clinical score of 1 ) on median at day 10 post-immunization. Mice were followed for 21 days after immunization. Baseline behaviour was assessed on three separate days before EAE induction. (C) EAE mice present mechanical hypersensitivity as indicated by a reduction in their von Frey thresholds. (D) In contrast, EAE mice at onset do not show a significant reduction in the time spent on the rotarod suggesting no or limited signs of hindpaw paralysis and lack of motor coordination. *** p<0.001, RM two-way ANOVA. (E) BiP, an ER chaperone, protein levels are elevated chronically in the disease. (F-H) Total eIF2 $\alpha(t-$ eIF2 $\alpha$ ) protein levels trend towards an increase with EAE disease course while its phosphorylated isoform ( $\mathrm{p}$-eIF2 $\alpha$ ) significantly increases at the chronic time point, suggesting that phosphorylation of (I-J) XBP1 and CHOP proteins are upregulated with disease onset and remain elevated chronically in the DRGs of EAE mice. (CFA: $n=4$, onset: $n=4$, chronic: $n=4$ ). (L-O) Further IHC analysis of XBP1 demonstrates a global increase in the transcriptionallyactive spliced XBP1 as nuclear staining within neurons. Further analysis revealed that small DRG neurons ( $<30 \mu \mathrm{m}$ in diameter) presented the greatest increased XBP1-positive nuclei. (L) Filled arrow-heads indicate XBP1-positive nuclei in DRG neurons whereas, empty arrowheads indicate XBP1-negative nuclei. (CFA: $n=5$, onset: $n=5$, chronic: $n=5$ ). Bars indicate mean \pm standard error of mean $(\mathrm{SEM})$. EAE = experimental autoimmune encephalomyelitis, $\mathrm{CFA}=$ complete Freund's adjuvant. *, \# p<0.05, ** $\mathrm{p}<0.01$, *** $\mathrm{p}<0.001$, one-way ANOVAs with Holm-Sidak's multiple comparison test.

\section{ER stress in the DRG of EAE mice}

We next assessed the expression of ER proteins in the DRG of mice with EAE over the course of the disease. The levels of BiP, a luminal ER chaperone, were elevated in the DRG at the chronic stage of the disease $\left(\mathrm{F}_{\mathrm{BiP}}(2,9)=7.950, \mathrm{p}=0.0103\right.$, One-way ANOVA) (Fig. 2E). Levels of phosphorylated eIF $2 \alpha$ (p-eIF2 $\alpha$ ) were significantly upregulated at the chronic time point whereas total eIF $2 \alpha(\mathrm{t}-\mathrm{eIF} 2 \alpha)$ levels only trended toward an increase with the progression of disease $\left(F_{\text {t-eIF2 } \alpha}(2,9)=3.808, p=0.0633, F_{p-e I F 2 \alpha}(2,9)=7.030, p=0.0145\right.$; One-way ANOVA) (Fig. $2 F, G)$. Hence, phosphorylation of eIF $2 \alpha$, as measured by the ratio of p-eIF $2 \alpha$ to t-eIF $2 \alpha$, was found to be increased at the chronic timepoint $\left(\mathrm{F}_{\mathrm{p}-\mathrm{eIF} 2 \alpha / \mathrm{t} \text {-eIF2 } \alpha}(2,9)=12.75, \mathrm{p}=0.0024\right.$; One-way 
ANOVA) (Fig. 2H). Interestingly, levels of the UPR transcription factors XBP1 and CHOP were upregulated at disease onset and remained elevated into the chronic phase $\left(\mathrm{F}_{\mathrm{XBP1}}(2,9)=18.59\right.$, $\mathrm{p}=0.0006 ; \mathrm{F}_{\mathrm{CHOP}}(2,9)=12.08, \mathrm{p}=0.0028$, One-way ANOVA) (Fig. 2I, J).

A key feature of the UPR involves IRE1 $\alpha$ splicing of XBP1 mRNA to generate a spliced isoform of XBP1 which acts as a potent transcription factor $(16,29)$. To further elucidate the cellular origin of XBP1, we performed an IHC experiment and discovered that the proportion of neurons with nuclear staining of XBP1 (nXBP1) was increased significantly in the DRG of mice with $\operatorname{EAE}\left(\mathrm{F}_{\text {total cells }}(2,12)=9.910, \mathrm{p}=0.0029\right.$, One-way ANOVA) (Fig. 2L, M). On closer inspection, smaller $(<30 \mu \mathrm{m})$ diameter neurons demonstrated a significant increase in $\mathrm{nXBP} 1$ expression with EAE while larger $(\geq 30 \mu \mathrm{m})$ diameter cells showed minimal change in $\mathrm{nXBP} 1$ levels. $\left(\mathrm{F}_{<30 \mathrm{um}}(2,12)=12.12, \mathrm{p}=0.0013 ; \mathrm{F}_{\geq 30 \mathrm{um}}(2,12)=0.3210, \mathrm{p}=0.7314\right.$, One-way ANOVA) (Fig. $2 \mathrm{~N}, \mathrm{O})$. These results suggest that the ER stress-pertinent spliced isoform of XBP1 is upregulated in small diameter, putative nociceptors in the DRG.

\section{4-PBA treatment alleviates mechanical and facial hypersensitivity}

Recently, the chemical chaperone, 4-phenylbutyric acid (4-PBA), has been shown to ameliorate neuropathic pain by reducing ER stress $(18,22,30)$. We wanted to investigate if daily systemic treatment with 4-PBA $(200 \mathrm{mg} / \mathrm{kg})$ starting at the onset of disease (Fig. 3A) would alter EAE disease course and relieve mechanical and orofacial hypersensitivity in mice with EAE. DRGs were then harvested after 7-10 days of treatment with either 4-PBA or vehicle (1x PBS). We did not observe any change in disease course following 4-PBA treatment $(\mathrm{F}(10,183)=0.2834$, $\mathrm{p}=0.9842$ ) (Fig. 3B). At the onset of clinical signs and before 4-PBA administration, we observed the characteristic reduction in von Frey thresholds in mice with EAE. One-hour after 4- 
PBA injection, the von Frey threshold recovered close to baseline levels. Vehicle administration did not have any behavioural effects $\left(F_{\text {interaction }}(2,42)=4.358, p=0.0191, F_{\text {treatment }}(2,42)=39.72\right.$, $\mathrm{p}<0.0001, \mathrm{~F}_{\text {group }}(1,21)=1.746, \mathrm{p}=0.2006, \mathrm{~F}_{\text {subjects }}(21,42)=1.713, \mathrm{p}=0.0681, \mathrm{RM}$ two-way ANOVA) (Fig. 3C). Due to the ensuing paralysis of the hind limbs at later stages in the disease, we could not assess hindpaw mechanical hypersensitivity 7-10 days post onset at the time of tissue harvest. Instead, we analysed orofacial pain behaviours (headshakes, single swipe, and continuous swipes) using an air puff assay (8). As compared to vehicle treated animals, daily 4PBA treatment dampened total facial pain behaviours by $50 \%$, headshakes by $66 \%$, single swipe by $50 \%$, and continuous swipes by $33 \%$ (Fig. 3D).

Figure 3

A

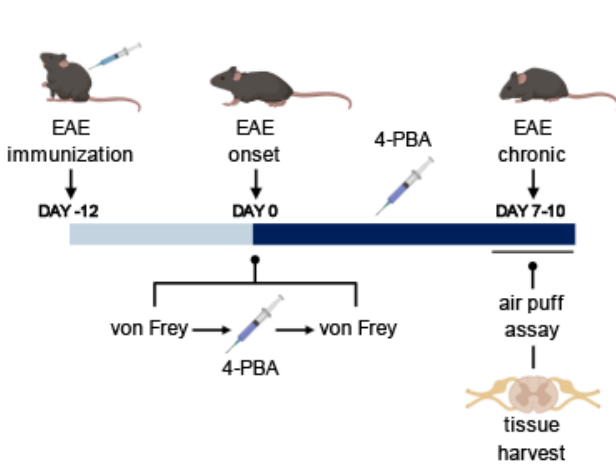

B

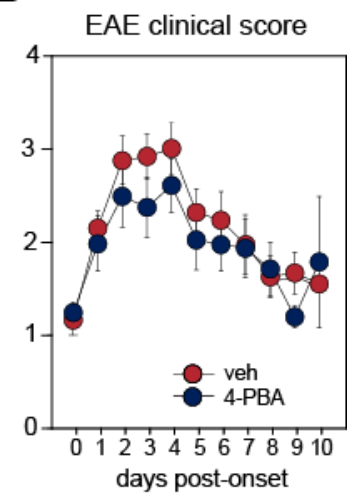

D

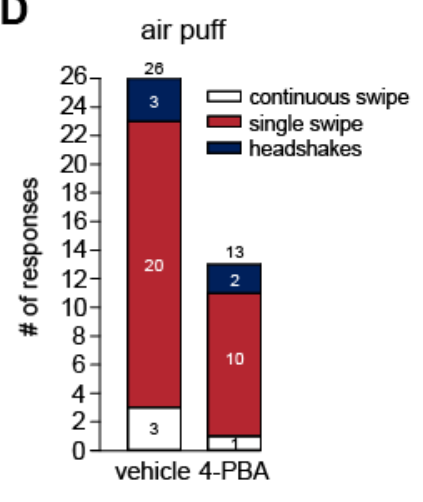


Figure 3. Daily 4-PBA treatment alleviates EAE-induced mechanical hypersensitivity. (A) Mice that were immunized with $\mathrm{MOG}_{35-55}$ developed EAE symptoms on median 12 days after induction. At disease onset (day 0), mice were subjected to von Frey filaments test followed by treatment with 4-PBA (intraperitoneal, $200 \mathrm{mg} / \mathrm{kg}, \mathrm{n}=12$ ) or vehicle (PBS, $\mathrm{n}=12$ ). An hour later, another von Frey filaments test was conducted. On subsequent days, mice were administrated 4PBA $(200 \mathrm{mg} / \mathrm{kg})$ daily. Mice underwent the air puff assay an hour after the final drug administration 7-10 days post onset after which they were euthanized. (B) 4-PBA treatment did not significantly alter EAE disease course. (C-D) As expected, von Frey thresholds were diminished in EAE animals as compared to baseline only to recover in the 4-PBA treated animals. (E) 4-PBA treated animals also showed a 50\% reduction in overall nociceptive behaviours (continuous swipe, single swipe, headshakes) in response to the air puff assay. ** p<0.01, RM two-way ANOVAs with Holm-Sidak's post-hoc analysis.

\section{4-PBA treatment does not alter inflammation and ER stress in the spinal dorsal}

\section{horn}

CNS inflammation has been linked to pain hypersensitivity in EAE mice (26). To assess whether the antinociceptive effects of 4-PBA were mediated by altered inflammatory responses in the superficial dorsal horn of the spinal cord (SDH), we quantified the levels of Iba1+ microglia/macrophages and CD4+ T-cells in this region (Fig. 4A, B). The levels of Iba1 and CD4 immunoreactivity were elevated in the SDH of both vehicle and 4-PBA treated animals and were not significantly different between treatments $\left(\mathrm{F}_{\mathrm{Iba} 1}(2,11)=17.38, \mathrm{p}=0.0004\right.$;

$\mathrm{F}_{\mathrm{CD} 4}(2,11)=32.88, \mathrm{p}<0.0001$, one-way ANOVA). Interestingly, XBP1 immunoreactivity was also increased in the SDH with disease but its expression was not affected with 4-PBA treatment $\left(\mathrm{F}_{\mathrm{XBP} 1}(2,11)=7.845, \mathrm{p}=0.0076\right.$, one-way ANOVA) $($ Fig. 4C). cFOS, a commonly used marker of cellular activity, was elevated in the SDH of EAE animals as shown previously (31). cFOS expression in the SDH of 4-PBA administered animals was however, normalized $\left(\mathrm{F}_{\mathrm{cFOS}}(2,12)=3.998, \mathrm{p}=0.0467\right.$, one-way ANOVA) (Fig. 4D). Collectively, these results suggest that 4-PBA's antinociceptive effects were not due to a change in immune activation or 
bioRxiv preprint doi: https://doi.org/10.1101/2020.01.22.915546; this version posted March 25, 2020. The copyright holder for this preprint (which was not certified by peer review) is the author/funder, who has granted bioRxiv a license to display the preprint in perpetuity. It is made available under aCC-BY-NC-ND 4.0 International license.

infiltration in the SDH nor can it be accounted for by a reduction in ER stress in this region.

Instead, the normalized levels of cFOS with 4-PBA treatment suggest a possible reduction in peripheral afferent drive into the spinal dorsal horn.

Figure 4
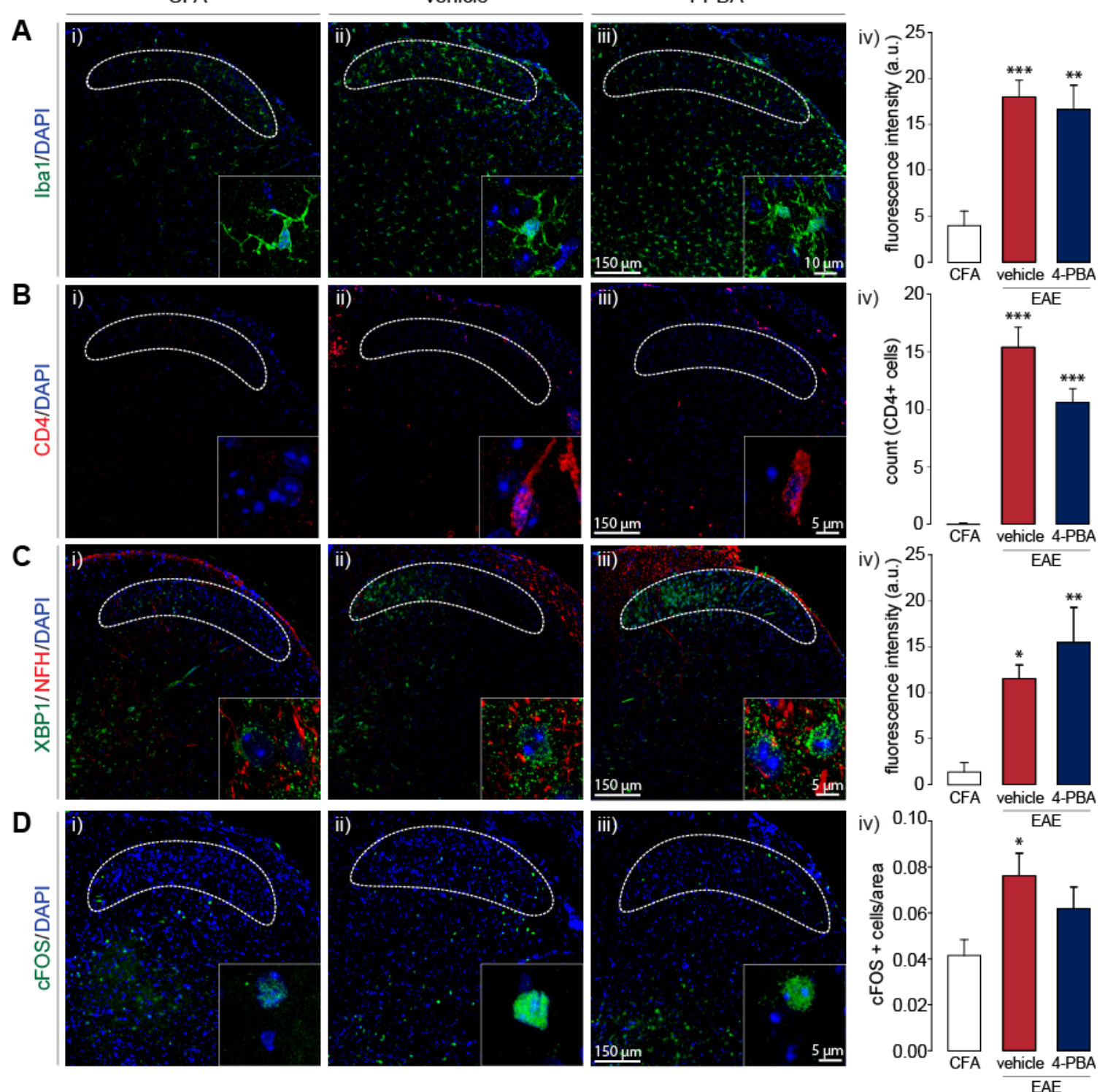
Figure 4. 4-PBA treatment does not alter spinal inflammation and ER stress. (A-C) As expected in an immune-mediated disease, substantial microglial activation (Iba1+), infiltration of T-cells (CD4+), and XBP1 immunoreactivity was observed in the spinal dorsal horn of vehicletreated animals 7-10 days post onset of EAE. However, 4-PBA treatment was not able to significantly reduce Iba1, CD4, and XBP1 immunoreactivity in the dorsal horn of these animals. (D) EAE enhanced cFOS expression in the dorsal horn of EAE mice. 4-PBA administration was able to rescue some of the disease-mediated increase in cFOS+ cells. $* \mathrm{p}<0.05, * * \mathrm{p}<0.01$, *** $\mathrm{p}<0.001$, one-way ANOVAs with Tukey's post-hoc analysis.

\section{4-PBA treatment reduces ER stress in the DRG}

To further investigate the mechanism of 4-PBA's beneficial effects on pain behaviours in EAE, levels of UPR-related proteins in the DRG were assessed after 4-PBA treatment (Fig. 5). The levels of the ER stress proteins, BiP and t-eIF2 $\alpha$, remained unchanged with 4-PBA treatment $\left(\mathrm{t}_{\mathrm{BiP}}(8)=0.4978, \mathrm{p}=0.6320 ; \mathrm{t}_{\mathrm{t}-\mathrm{eIF} \alpha}(8)=1.110, \mathrm{p}=0.1495 ;\right.$ unpaired $\mathrm{t}$-test $)$ (Fig. 5A, B). However, we observed significant reductions in the phosphorylation of eIF2 $\alpha, \mathrm{XBP} 1$, and CHOP levels in DRG samples of mice treated with 4-PBA as compared to vehicle administration $\left(t_{\mathrm{p}-}\right.$

$\operatorname{eIF2\alpha }(8)=3.282, \mathrm{p}=0.0112 ; \mathrm{t}_{\mathrm{p}-\mathrm{eIF} 2 \alpha / \mathrm{t}-\mathrm{eiF} 2 \alpha}(8)=3.816, \mathrm{p}=0.0051 ; \mathrm{t}_{\mathrm{XBP} 1}(8)=2.517, \mathrm{p}=0.0360 ;$

$\mathrm{t}_{\mathrm{CHOP}}(8)=2.697, \mathrm{p}=0.0272$; unpaired $\mathrm{t}$-test) $($ Fig. $5 \mathrm{C}-\mathrm{F})$. Taken together, these findings suggest that 4-PBA's antinociceptive effects were due to its ability to dampen ER stress in the DRG, particularly the levels of p-eIF2 $\alpha, \mathrm{XBP} 1$, and $\mathrm{CHOP}$, each of which represent different pathways of ER stress-induced UPR. 
Figure 5

A

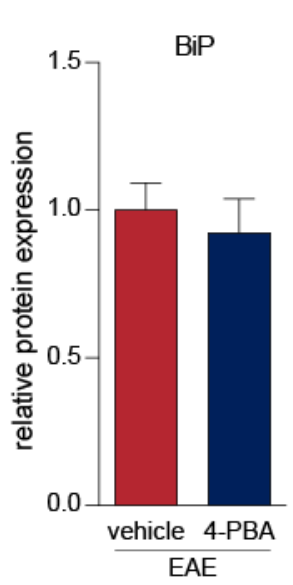

E

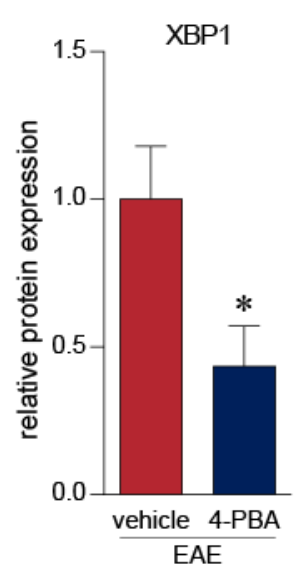

B

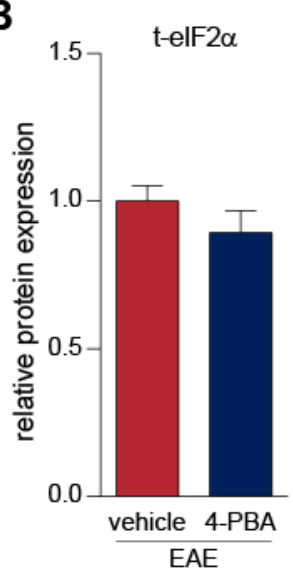

$\mathbf{F}$

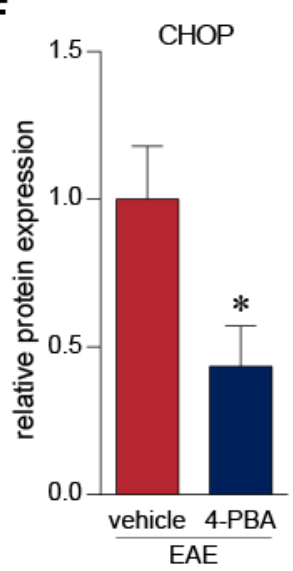

C

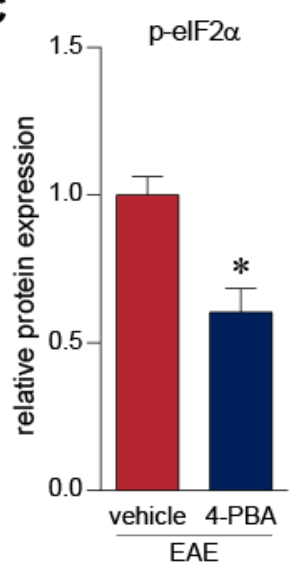

$\mathbf{G}$

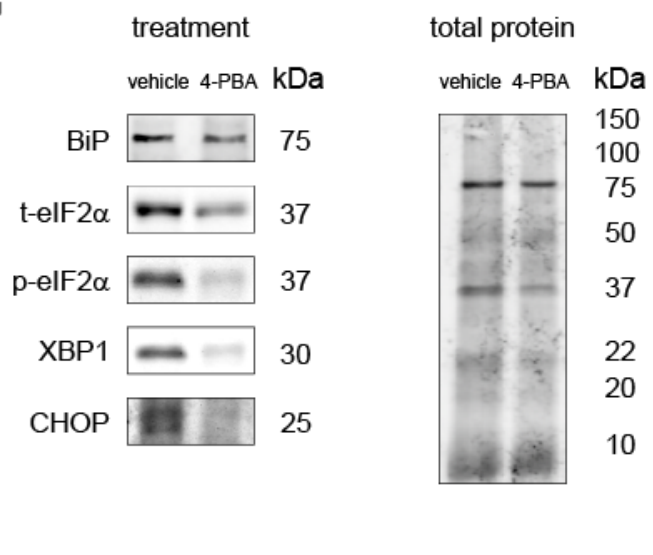

Figure 5. 4-PBA treatment reduces the expression of UPR-associated proteins in the DRG. (A-G) Western blot analysis of DRG samples from 4-PBA treated mice demonstrate a reduction in the levels of UPR-associated proteins. In particular, phosphorylation of eIF2 $\alpha$, XBP1 and CHOP levels were significantly downregulated in the DRGs of 4-PBA treated EAE mice. (vehicle: $\mathrm{n}=5$, 4-PBA: $\mathrm{n}=5$ ) ${ }^{*} \mathrm{p}<0.05$, unpaired t-test.

\section{4-PBA dampens $\mathrm{Ca}^{2+}$ responses in small diameter neurons}

4-PBA, or its salt sodium 4-phenylbutyrate, can alleviate ER stress primarily as a chemical chaperone (32) (Fig. 6A). To further investigate the impact of 4-PBA on neuronal function, we imaged cytosolic $\mathrm{Ca}^{2+}$ transients in dissociated DRG neurons from EAE animals upon caffeine $(20 \mathrm{mM})$ and $\mathrm{KCl}(30 \mathrm{mM})$ stimulation (Fig. 6B). Caffeine is known to sensitize ryanodine receptors to cytosolic $\mathrm{Ca}^{2+}$ leading to a $\mathrm{Ca}^{2+}$-induced calcium release (CICR) from the ER . 
Consistent with a reduction of ER stress-mediated hyperactivation of $\mathrm{Ca}^{2+}$ signaling, 4-PBA treatment reduced the amplitude of caffeine and $\mathrm{KCl}$-mediated $\mathrm{Ca}^{2+}$ rises in small $(<30 \mu \mathrm{m})$, diameter cells $\left(\mathrm{t}_{\text {Caffeine }}(149)=3.236, \mathrm{p}=0.0015 ; \mathrm{t}_{\mathrm{KCl}}(185)=2.238, \mathrm{p}=0.0264\right.$, unpaired $\left.\mathrm{t}-\mathrm{test}\right)$ (Fig. 6C-F). 4-PBA reduced mRNA levels of Ddit3, Xbpl, and Hspa5 indicating a reduction in ER stress $\left(\mathrm{t}_{\mathrm{Ddit} 3}(6)=2.165, \mathrm{p}=0.0735 ; \mathrm{t}_{\mathrm{Xbp} 1}(6)=3.511, \mathrm{p}=0.0127, \mathrm{t}_{\mathrm{Hspa}}(6)=3.511, \mathrm{p}=0.0155\right.$, unpaired t-test) (Fig. 6-1). These results suggest that 4-PBA reduces CICR and $\mathrm{KCl}$ mediated excitability in small diameter cells of the DRG from EAE mice by dampening ER stress.

Figure 6
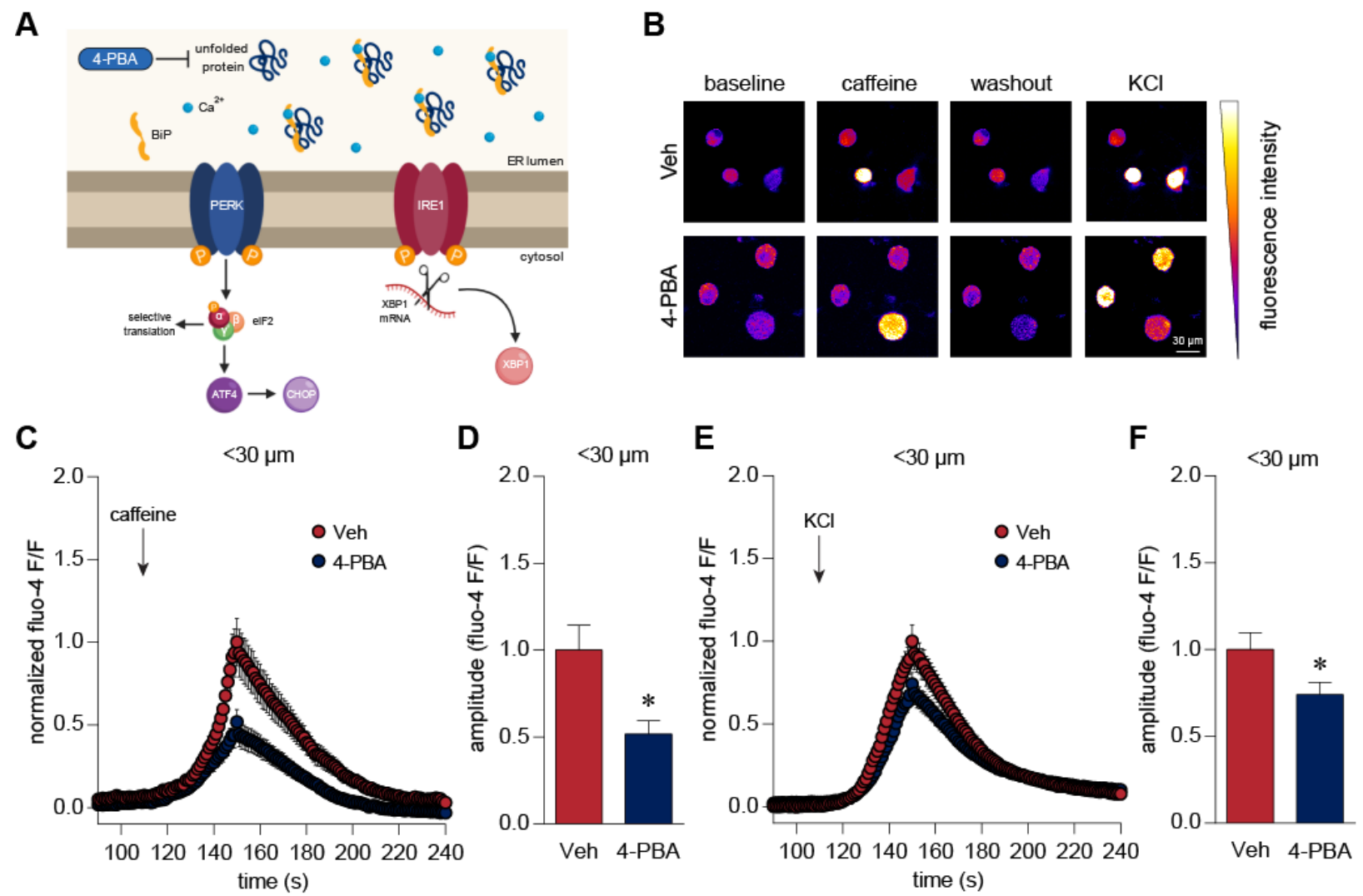

Figure 6. 4-PBA diminishes cellular $\mathrm{Ca}^{2+}$ responses in small-diameter DRG neurons. (A) As a chemical chaperone, 4-PBA aims to reduce unfolded protein response at the source by aiding in protein folding and dampening the accumulation of unfolded/misfolded proteins. (B-F) $\mathrm{Ca}^{2+}$ imaging of small $(<30 \mu \mathrm{m})$ dissociated neurons at onset show reduced $\mathrm{Ca}^{2+}$ rises in 4-PBA treated neurons $(\mathrm{n}=113)$ upon caffeine $(20 \mathrm{mM})$ and $\mathrm{KCl}(30 \mathrm{mM})$ stimulation. Responses were normalized to the $\mathrm{Ca}^{2+}$ responses in the vehicle (HBSS) treated group $(\mathrm{n}=74)$. Data were analysed as a ratio of baseline fluorescence. ${ }^{*} \mathrm{p}<0.05$, unpaired t-test. 


\section{Knockdown of Ddit3 and Xbp1 mRNA does not alter evoked $\mathrm{Ca}^{2+}$ rises}

Earlier, we observed a reduction in $\mathrm{CHOP}$ and $\mathrm{XBP} 1$ in vivo after treatment with 4-PBA. To

ascertain the contribution of these transcription factors to enhanced $\mathrm{Ca}^{2+}$ signalling observed in EAE cells (Fig. 6; Mifflin et al., 2019), we silenced gene expression of CHOP (encoded by Ddit3) and Xbpl in dissociated DRG neurons from EAE animals (Fig. 7A). Neither XBP1 nor CHOP siRNA treatment changed cytosolic $\mathrm{Ca}^{2+}$ rises upon caffeine and $\mathrm{KCl}$ stimulation $\left(\mathrm{F}_{\text {Caffeine }}(2,221)=0.5593, \mathrm{p}=0.5724, \mathrm{~F}_{\mathrm{KCl}}(2,268)=1.119, \mathrm{p}=0.3282\right.$, one-way ANOVA) $($ Fig. $7 \mathrm{~B}-$ F). As confirmation of the siRNA efficacy, XBP1 and CHOP siRNA reduced the expression of their respective genes, $\mathrm{Xbpl}$ and Ddit3, as well as Hspa5 (BiP) which may be induced by both $\mathrm{XBP} 1$ and $\mathrm{CHOP}\left(\mathrm{F}_{\mathrm{Xbp} 1}(2,12)=32.13, \mathrm{p}<0.0001, \mathrm{~F}_{\mathrm{Ddit} 3}(2,12)=25.67, \mathrm{p}<0.0001\right.$, $\mathrm{F}_{\mathrm{Hspa}}(2,12)=5.020, \mathrm{p}=0.0260$, one-way ANOVA) (Fig. 7G-I). Moreover, in order to further assess the efficacy of the transfection system, we transfected dissociated neurons with Alexa Fluor 488-conjugated nonsilencing siRNA which has no known homology to any mammalian gene (Fig. 7J). The presence of this siRNA in our neurons suggested that our experimental siRNAs were indeed being delivered into the neurons. Altogether, these data indicate that a selective reduction in either $\mathrm{CHOP}$ or XBP1 is not sufficient to reduce CICR or $\mathrm{KCl}$ excitability in dissociated DRG neurons from EAE animals. 
Figure 7

A

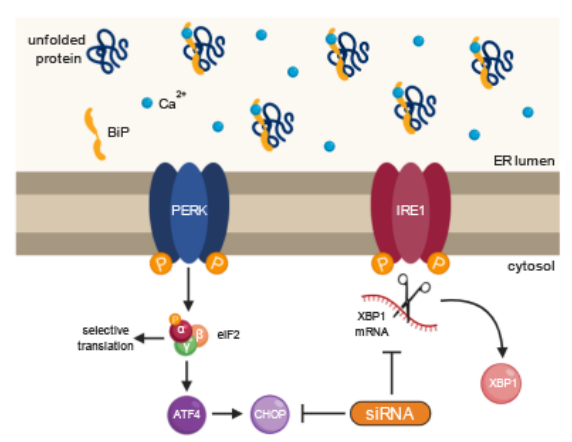

C
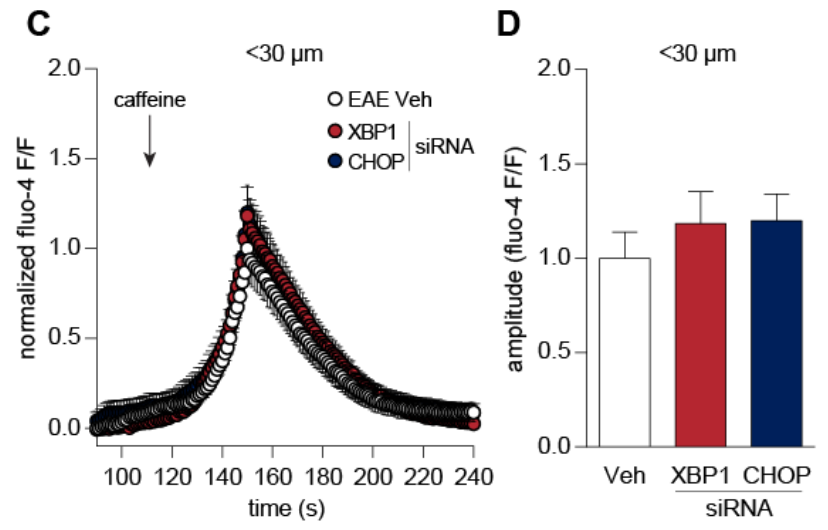

G

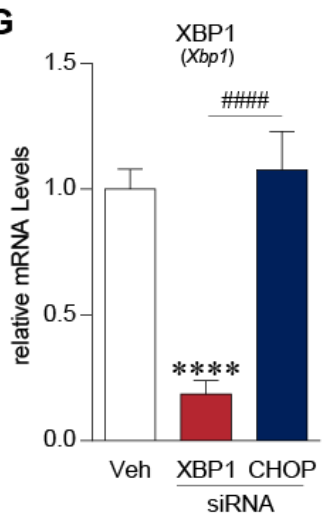

H

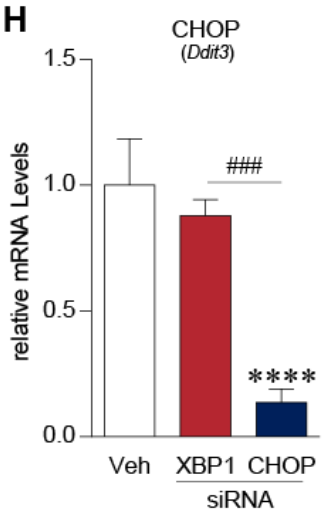

B

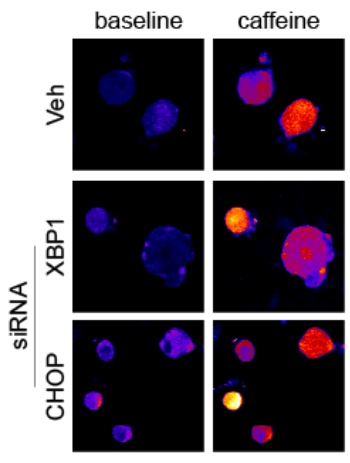

E

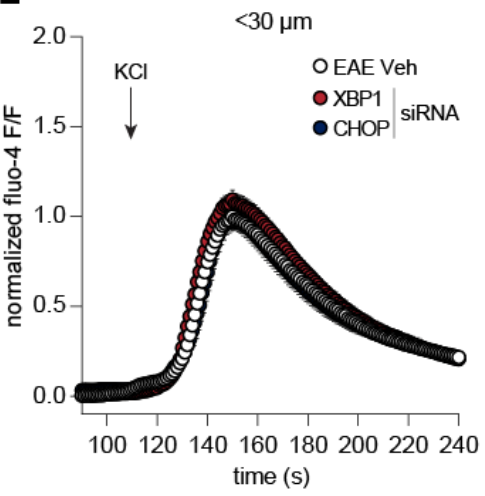

J
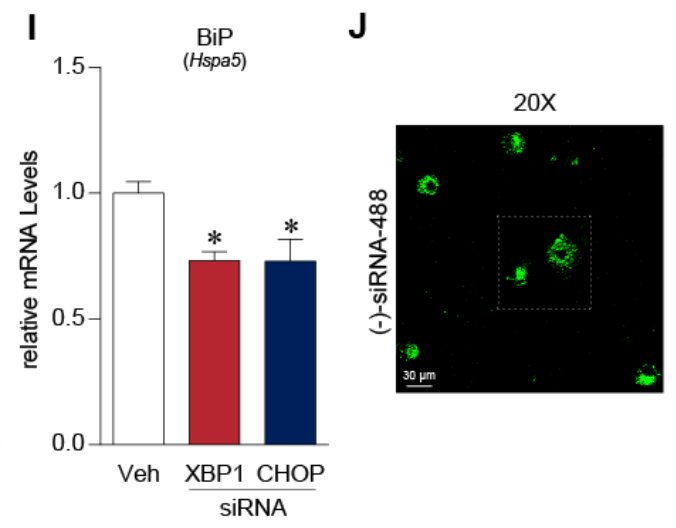

washout
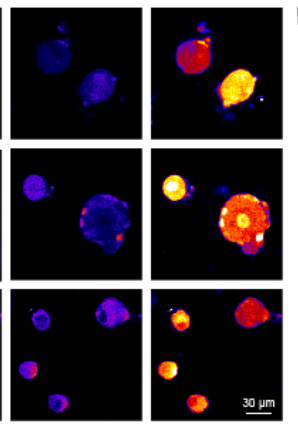

F

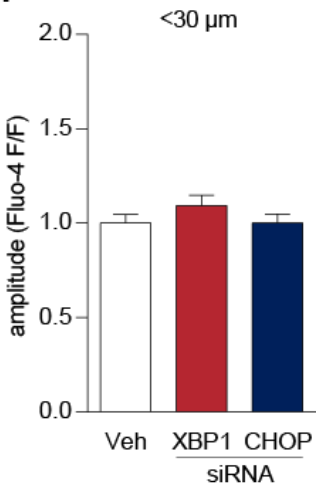

$60 x$

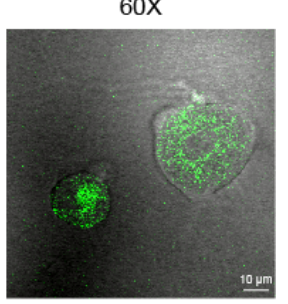




\section{Figure 7. Gene knockdown of XBP1 and CHOP did not alter $\mathrm{Ca}^{2+}$ transients in small- diameter DRG neurons. (A) siRNA transfection knocked down expression of CHOP and XBP1 mRNA. (B-E). Dissociated EAE cells were transfected with XBP1 $(n=77)$ and CHOP $(n=100)$ siRNA 20-24 hours prior to $\mathrm{Ca}^{2+}$ imaging. We observed no change in the $\mathrm{Ca}^{2+}$ transients of EAE DRG neurons during stimulation with caffeine $(20 \mathrm{mM})$ or $\mathrm{KCl}(30 \mathrm{mM})$ after siRNA knockdown of XBP1 and CHOP as compared to vehicle (transfection reagent HiPerfect) treated EAE neurons $(n=94)$. $(\mathrm{G}, \mathrm{H})$ As confirmation, PCR analysis of transfected DRG neurons demonstrated a drastic reduction in their respective gene. XBP1 transcript expression was dampened in XBP1 siRNA treated cells $(\mathrm{n}=5)$ and similarly, CHOP mRNA levels were diminished upon CHOP siRNA treatment $(n=5)$ as compared to vehicle-treated cells $(n=5)$. (I) We observed that BiP (Hspa5) expression was also reduced upon knockdown of XBP1 and CHOP mRNA. (J) To further validate our siRNA delivery system, we transfected cells with a negative siRNA tagged with Alexa Fluor 488. We found that dissociated neurons were transfected with (-)-siRNA using our delivery system further suggesting that XBP1 and CHOP siRNA were successfully delivered in our primary neurons. ${ }^{\# \#} \mathrm{p}<0.001$; ****, \#\#\# $\mathrm{p}<0.0001$, one-way ANOVAs with Tukey's post-hoc analysis.}

\section{The PERK inhibitor, AMG44, reduces $\mathrm{Ca}^{2+}$ signalling in small diameter neurons}

Upon ER stress, PERK autophosphorylates, oligomerizes, and subsequently phosphorylates eIF2 $\alpha$ (16).Western blotting of DRGs obtained from EAE mice at disease onset show increased phosphorylation of PERK $(\mathrm{t}(7)=4.554, \mathrm{p}=0.0026$, unpaired t-test) (Fig. 8A). To investigate the contribution of ER stress-mediated and PERK induced eIF2 $\alpha$ activation, we treated DRG cells from EAE animals with a novel PERK inhibitor, AMG PERK 44 (AMG44) (33) (Fig. 8B). CICR amplitude, as measured by caffeine stimulation, and $\mathrm{KCl}$ depolarization is enhanced in vehicle (0.1\% DMSO) treated EAE cells as compared to DRG neurons obtained from CFA mice. AMG44 treatment normalizes both caffeine and $\mathrm{KCl}$ induced $\mathrm{Ca}^{2+}$ rises in small $(<30 \mu \mathrm{m})$ diameter neurons $\left(\mathrm{F}_{\text {Caffeine }}(2,171)=3.391, \mathrm{p}=0.0360, \mathrm{~F}_{\mathrm{KCl}}(2,209)=4.146, \mathrm{p}=0.0171\right.$, one-way ANOVA) (Fig. 8C-G). PCR analysis of dissociated DRG cells revealed that Ddit3 or CHOP transcripts were reduced with AMG44 treatment as compared to vehicle treated EAE cells $(t(8)=7.013, p=0.0001$, unpaired $t$-test $)$. Furthermore, AMG44 treatment increased the expression 
of Xbpl and Hspa5 transcripts $\left(\mathrm{t}_{\mathrm{Xbp} 1}(8)=2.865, \mathrm{p}=0.0210 ; \mathrm{t}_{\mathrm{Hspa}}(8)=2.738, \mathrm{p}=0.0255\right.$, unpaired $\mathrm{t}-$ test) (Fig. 6-1) suggesting that intervening with the PERK arm of UPR allows for a shift towards a more protective IRE1-XBP1-BiP branch of the UPR.

Figure 8

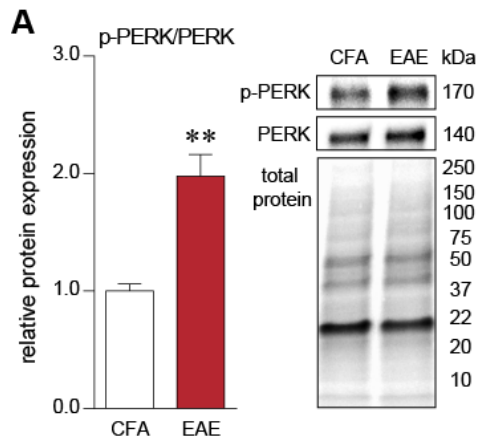

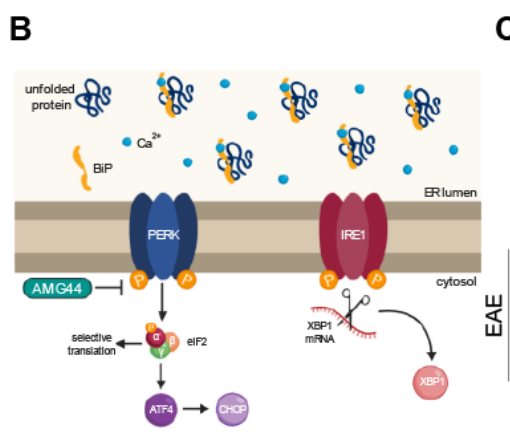

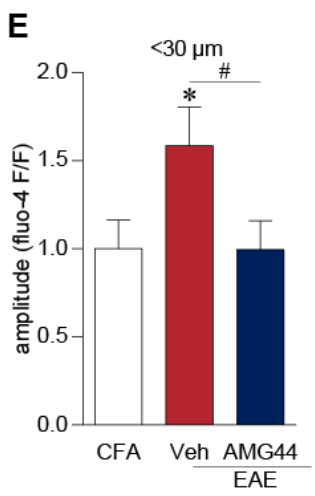

$\mathbf{F}$
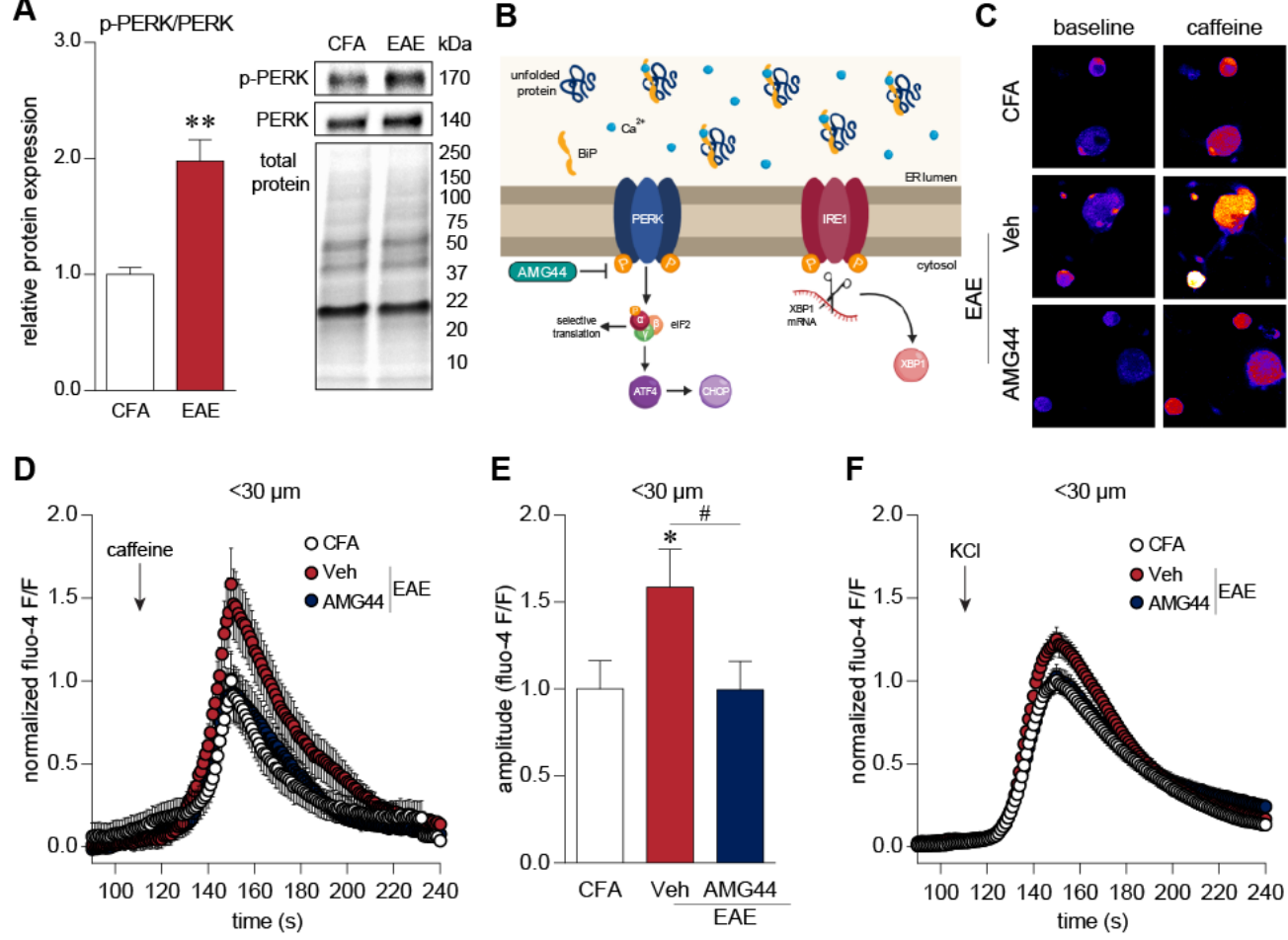

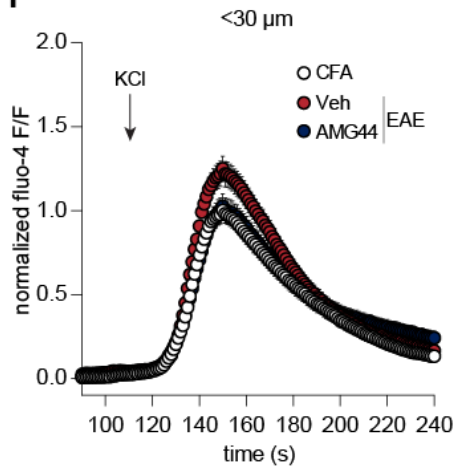

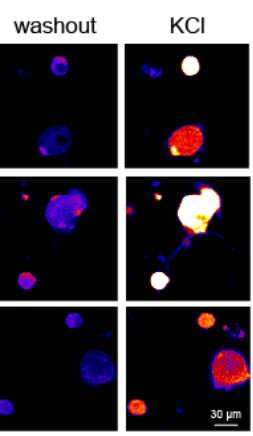

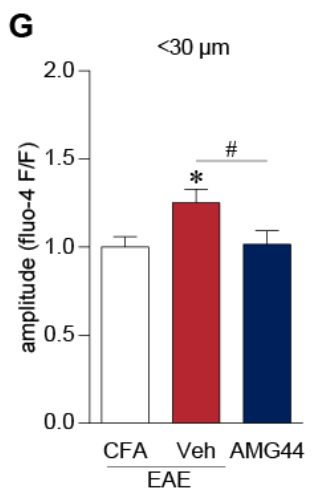

Figure 8. AMG44 treatment dampens cytosolic $\mathrm{Ca}^{2+}$ responses in small-diameter DRG neurons. (A) Phosphorylation of PERK is increased in EAE DRGs $(n=5)$ at disease onset as compared to DRGs from CFA control mice $(n=4)$. ${ }^{*}$ p $p<0.01$, unpaired t-test. (B) AMG44, a recently identified PERK inhibitor, aims to prevent PERK phosphorylation and thereby block the PERK-eIF2 $\alpha$ signalling in response to ER stress. (C-F). Vehicle treated (0.01\% DMSO) EAE neurons $(\mathrm{n}=74)$ demonstrate enhanced $\mathrm{Ca}^{2+}$ responses upon caffeine $(20 \mathrm{mM})$ and $\mathrm{KCl}(30 \mathrm{mM})$ administration as compared to vehicle-treated dissociated neurons obtained from CFA-control animals $(n=70)$. These transients are normalized with AMG44 treatment $(n=68)$ suggesting that the PERK-eIF2 $\alpha$ arm mediates $\mathrm{Ca}^{2+}$-induced $\mathrm{Ca}^{2+}$ release from the ER as well as cytosolic $\mathrm{Ca}^{2+}$ dynamics *, " $\mathrm{p}<0.05$, one-way ANOVAs with Tukey's post-hoc analysis. 


\section{BK channel current is rescued by 4-PBA and AMG44 treatment}

In a previous study (10), we noted a reduction in the afterhyperpolarization amplitude of small diameter, putative nociceptive neurons from mice with EAE. $\mathrm{Ca}^{2+}$ is known to alter the function of $\mathrm{Ca}^{2+}$-sensitive $\mathrm{K}^{+}$channels and hence, we asked whether $\mathrm{BK}$ channel properties are modified with EAE disease considering the altered $\mathrm{Ca}^{2+}$ dynamics we observed earlier. In order to prevent dialysing intracellular calcium, we performed amphotericin B perforated patch clamp recordings. We found paxilline-sensitive BK channel current almost exclusively in small diameter IB4+ neurons similar to previous reports (Fig. 9A, D) (34). We also found that the conductancevoltage $(\mathrm{GV})$ curve was right-shifted in IB4+ EAE neurons as compared to neurons from CFA animals suggesting that BK channel activity was modified in EAE (Fig. 9B, E). 4-PBA and AMG44 treatment normalized the GV relationship of the BK channels (Fig. 9C, F). EAE responses (red) are the same in Fig. 9B and C. In effect, $0 \mathrm{mV}$ test voltage (red trace) minimally activated paxilline-sensitive BK currents in EAE neurons compared to other conditions illustrating the strong shift in voltage-dependent gating of BK channels in EAE neurons (red trace; Fig. 9E, F). The conductance-voltage relationship was quantified as the voltage required for half the maximum conductance (i.e. $\left.V_{1 / 2}\right)$ across the cell membrane (Fig. 9G) $(F(3,34)=6.631$, $\mathrm{p}=0.0012$, one-way ANOVA). The current density was not significantly altered (Fig. 9H) $(\mathrm{F}(3,18)=1.525, \mathrm{p}=0.2421$, one-way ANOVA $)$. However, the resting membrane potential was more depolarized in IB4+ neurons from EAE animals as compared to IB4+ control neurons, suggesting that the inherent resting state of the EAE cell was altered due to the disease. 4-PBA and AMG44 treatment in vitro rectified changes in the resting membrane potential of EAE cells (Fig. 9I) $(\mathrm{F}(3,19)=11.11, \mathrm{p}=0.0002$, one-way ANOVA). 
Figure 9

A

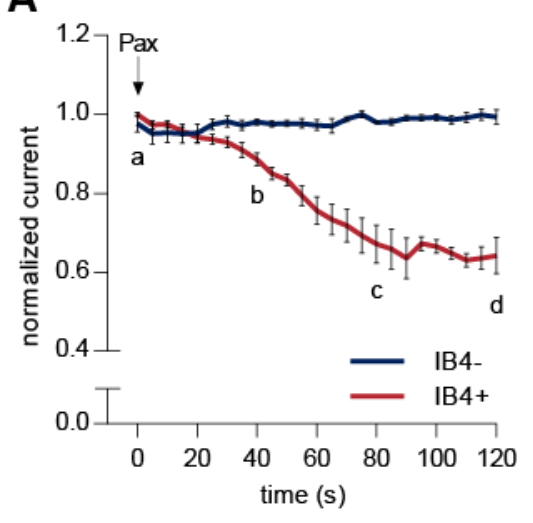

D

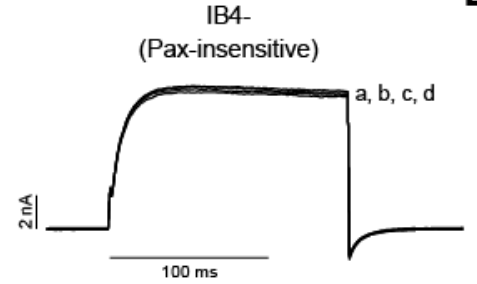

IB4+

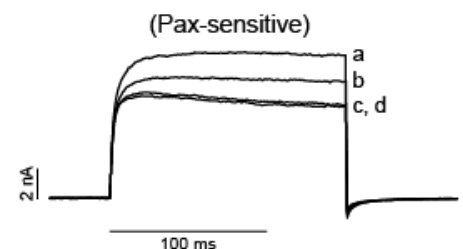

B

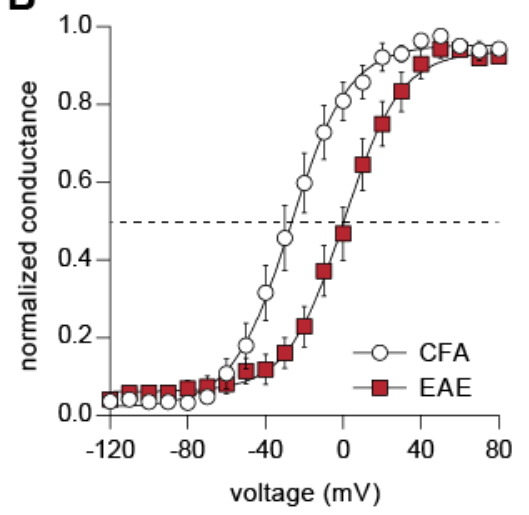

E

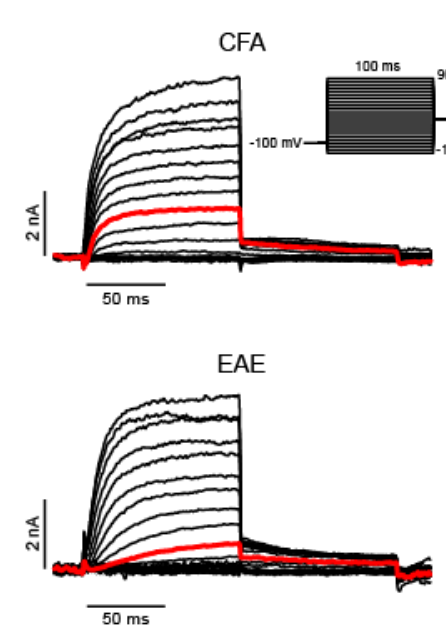

C

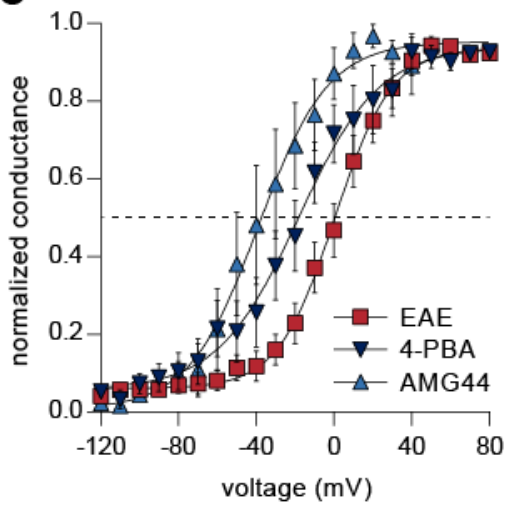

F

4-PBA
G

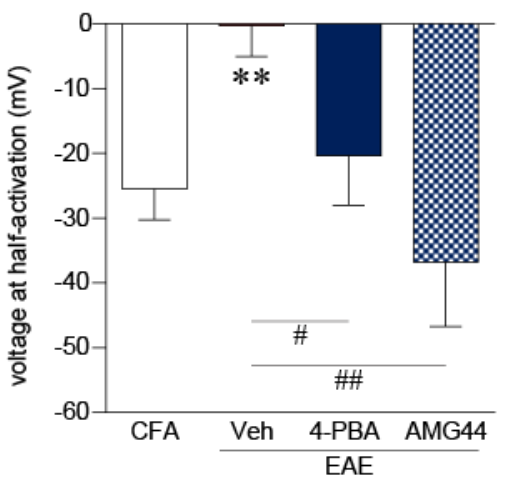

H

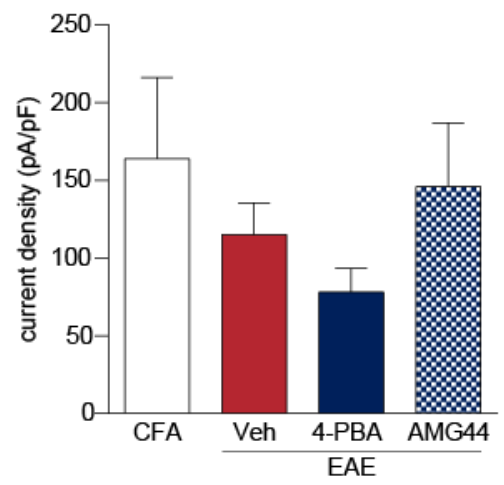

I

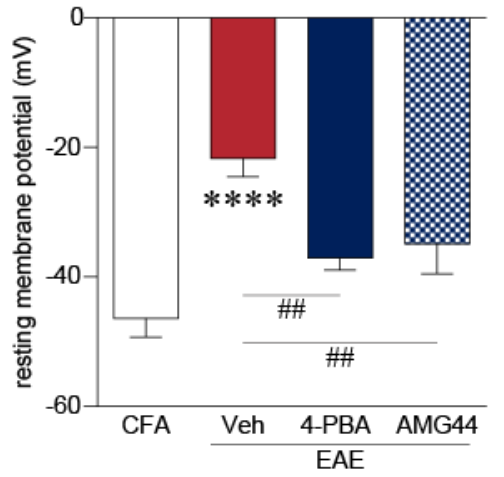




\begin{abstract}
Figure 9. ER stress modulators rescue EAE-mediated changes in $\mathrm{Ca}^{2+}$-sensitive $\mathrm{BK}$ channel properties. (A, D) Perforated patch-clamp recordings of DRG neurons from naïve animals revealed that paxilline-sensitive BK current was almost exclusively present in IB4+ nonpeptidergic neurons. (D) Exemplar BK currents of IB4- and IB4+ neurons in response to paxilline application at $0(\mathrm{a}), 40(\mathrm{~b}), 80$ (c), 120 (d) seconds. (B, C) Conductance-voltage $(\mathrm{G}-\mathrm{V})$ relationship among paxilline-sensitive IB4+ DRG neurons extracted from (B) CFA and EAE mice, and (C) EAE neurons treated with 4-PBA and AMG44. Solid lines represent Boltzmann fit of the $\mathrm{G}-\mathrm{V}$ relationship. Intersection of the Boltzmann curve and the dotted line represents voltage at half conduction (E, F) Representative traces of IB4+ neurons from CFA and EAE animals as well as EAE neurons treated with 4-PBA and AMG44. Red trace indicates BK channel conductance at $0 \mathrm{mV}$. (G) Conductance-voltage relationship was quantified as voltage at half-activation $\left(\mathrm{V}_{1 / 2}\right)$ of $\mathrm{BK}$ channels. Vehicle treated EAE neurons $(\mathrm{n}=15)$ demonstrated a more positive $V_{1 / 2}$ in comparison to CFA neurons $(n=12)$. This effect was reversed with 4-PBA $(n=7)$ and AMG44 $(n=4)$ treatment. $(\mathrm{H}) \mathrm{BK}$ current density in IB4+ neurons was not found to be significantly altered. CFA: $n=5$, Veh: $n=6,4-P B A: n=7, A M G 44: n=4$. (I) Resting membrane potential was found to be more depolarized in the vehicle treated EAE neurons $(n=9)$ as compared to CFA control neurons $(n=5)$. This was reversed with treatment with ER stress modulators, 4-PBA $(\mathrm{n}=4)$ and AMG44 $(\mathrm{n}=5) .{ }^{\#} \mathrm{p}<0.05, * *,{ }^{\# \#} \mathrm{p}<0.01$, **** $\mathrm{p}<0.0001$, one-way ANOVAs with Holm-Sidak multiple comparison test.
\end{abstract}

\title{
Auxiliary $\beta 4$ subunit is affected in MS and EAE
}

In order to investigate the molecular underpinnings of this phenomenon, we assessed the mRNA expression of the pore-forming $\alpha 1$ subunit (Kcnmal) and the auxiliary $\beta 1$ and $\beta 4$ subunits (Kcnmbl and Kcnmb4, respectively) of the BK channel in human and mouse DRGs. Transcripts of these BK channel subunits have been found to be enriched in non-peptidergic sensory neurons (35). We found a significant loss of $\beta 4$ subunit transcripts in human DRG samples from MS patients as compared to non-demented controls $\left(\mathrm{t}_{\mathrm{KCNMB}} 4(8.943)=2.993, \mathrm{p}=0.0152\right.$, unpaired $\mathrm{t}$-test with Welch's correction) (Fig. 10A). Similarly, DRGs from EAE animals also showed a loss of Kcnmb4 transcripts $\left(\mathrm{t}_{\mathrm{KCNMB} 4}(6.985)=3.034, \mathrm{p}=0.0191\right.$, unpaired $\mathrm{t}$-test with Welch's correction $)$

(Fig. 10B). In vitro, 4-PBA and AMG44 treatment increased Kcnmb4 expression in EAE neurons $\left(\mathrm{t}_{4-\mathrm{PBA}}(6)=2.731, \mathrm{p}=0.0341 ; \mathrm{t}_{\mathrm{AMG} 44}(8)=2.689, \mathrm{p}=0.0275\right.$, unpaired t-test $)$ (Fig. 10C, D). Likewise, 
the expression of $\beta 1$ subunit transcripts $(K c n m b 1)$ was reduced in whole DRGs obtained from

EAE animals and the loss of Kcnmbl expression was rectified with 4-PBA and AMG44

treatment in vitro $\left(\mathrm{t}_{\mathrm{MS}}(11)=0.7320, \mathrm{p}=0.4795 ; \mathrm{t}_{\mathrm{EAE}}(9)=3.784, \mathrm{p}=0.0043 ; \mathrm{t}_{4-\mathrm{PBA}}(6)=3.132\right.$,

$\mathrm{p}=0.0203 ; \mathrm{t}_{\mathrm{AMG} 44}(8)=2.574, \mathrm{p}=0.0329$, unpaired t-test) (Fig. 10-1). These data suggest that

disease-induced ER stress alters BK channel functioning by modulating auxiliary subunits, particularly the $\beta 4$ subunit, in IB4+ sensory neurons.

Figure 10
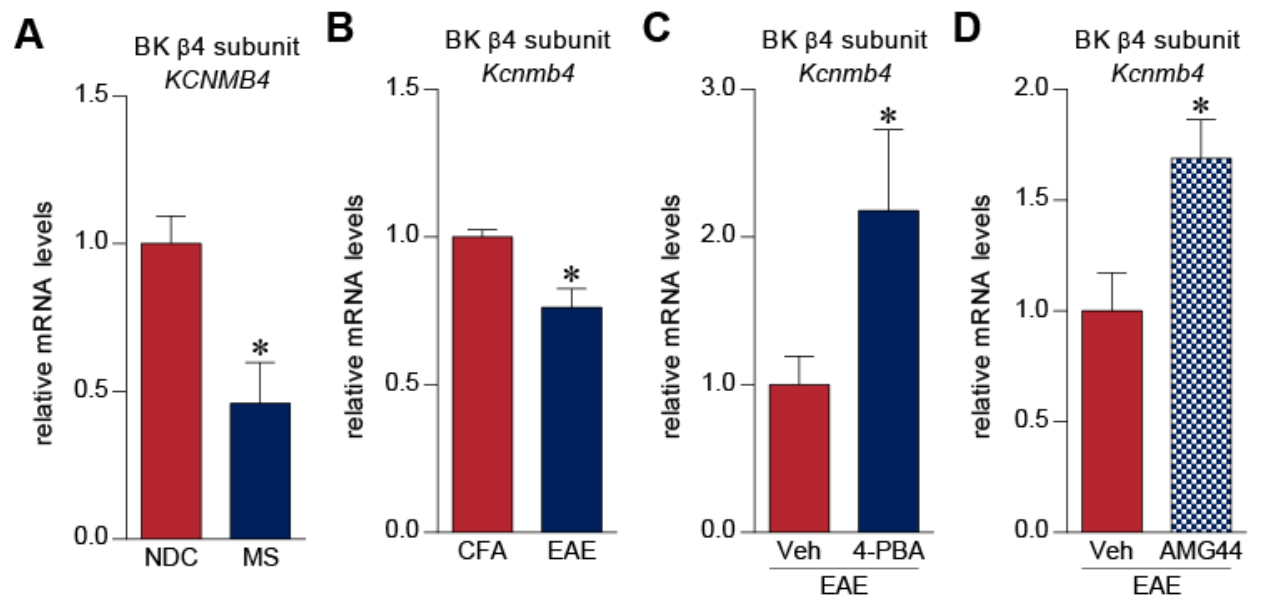

Figure 10. ER stress modulators rescues EAE-mediated changes in $\mathrm{Ca}^{2+}$-sensitive $\mathrm{BK}$ channel properties. (A) PCR analysis of post-mortem DRGs extracted from MS patients $(n=8)$ revealed that the BK $\beta 4$ subunit (KCNMB4) mRNA expression was reduced in MS as compared to DRGs from non-demented controls $(n=5)$. (B) Similarly, we observed a loss of Kcnmb4 mRNA in EAE samples $(n=7)$ coinciding with pain behaviours in these animals. $(\mathrm{C}, \mathrm{D})$ In vitro application of 4-PBA $(n=4)$ and AMG44 $(n=5)$ enhanced the expression Kcnmb4 transcripts correlating with the normalization of BK current in diseased neurons. ${ }^{*} \mathrm{p}<0.05$, unpaired t-test. 


\section{DISCUSSION}

Our results show for the first time that post-mortem DRGs from MS patients show evidence of inflammation and immune activation as well as increased expression of ER stress markers. These observations demonstrate that MS pathology extends beyond the CNS into the PNS. Several recent reports have implicated ER stress in mediating pain hypersensitivity in various models of neuropathy, including diabetic neuropathy $(18,20,36)$, spinal nerve ligation $(24,37)$, vasculitic peripheral neuropathy (22) and CFA-induced orofacial neuropathy (38). Although MS, like many other neurodegenerative disorders, has previously been associated with ER stress $(15,16,39)$, prior reports have largely focused on studying ER stress and the integrated stress response (ISR) in oligodendrocytes in EAE in the context of CNS demyelination (40-42). In contrast, our study highlights a novel role of ER stress in sensory neurons of the PNS for mediating pain in MS/EAE.

Application of 4-PBA has been shown to improve metabolic syndromes, congenital and genetic protein misfolding disorders, inflammation, and neurological disorders such as Parkinson's disease and ischemic brain injury (43). Daily administration of 4-PBA in our study ameliorated acute mechanical hypersensitivity as well as chronic facial pain behaviours without altering the clinical signs of the disease (Fig. 3). A previous study using 4-PBA in EAE, observed that treatment with 4-PBA (400 mg/kg/day) at the time of disease induction reduced clinical signs of EAE (44). Our current study employs a different variant of the EAE model. Additionally, we designed our study with 4-PBA administration beginning at the onset of clinical signs of EAE to limit the effects of reduced disease severity and its impact on pain behaviours. We were interested in investigating the role of ER stress on pain hypersensitivity in EAE rather than the effect of 4-PBA on the disease itself. Evidently, once EAE has been initiated, 4-PBA 
administration does not alter EAE disease course or immune activation in the dorsal spinal cord (Fig. 3, 4). In the DRG, however, 4-PBA broadly reduced levels of ER stress related proteins (Fig. 5).

The ISR has previously been implicated in pain pathophysiology $(19,36)$ as well as EAE $(45,46)$. The ISR pathway involves the phosphorylation of eIF2 $\alpha$ by an assortment of kinases PERK, protein kinase R (PKR), heme-regulated eIF2 $\alpha$ kinase (HRI), and general control nonderepressible 2 kinase (GCN2) - each of which is initiated by a variety of stressors $(47,48)$. Phosphorylation of eIF $2 \alpha$ allows the cell to rapidly respond to a stressor by reducing translation of certain genes and increasing translation of others, especially genes with upstream open reading frame (uORF) including, but not limited to, ATF4 and CHOP. Selective translation of genes that may enhance the excitability of sensory neurons in the context of pain, particularly IB4+ nociceptors, has recently been reported (36). ISR inhibitor (ISRIB) is a commonly used compound to suppress the effects of p-eIF2 $\alpha$ without altering its levels (49) however the initiating stressors (e.g. UPR, viral infection, amino acid deprivation etc.) and associated kinase activation remain ambiguous. In this study, we hoped to isolate the functional effects of UPRmediated PERK signalling using a recently developed inhibitor of PERK phosphorylation, AMG44 (33). We found that AMG44 in vitro could suppress caffeine stimulated CICR and $\mathrm{KCl}$ mediated $\mathrm{Ca}^{2+}$ excitability in small diameter cells while gene knock-down of CHOP and XBP1 had no effect on $\mathrm{Ca}^{2+}$ responses of sensory neurons (Fig. 7, 8). AMG44 also normalized BK channel physiology in dissociated DRGs from EAE mice as well as mRNA levels of the $\beta 4$ and $\beta 1$ auxiliary subunits of BK channels (Fig. 9, 10, 10-1). Taken together, these results suggest that EAE mediated activation of PERK in IB4+ sensory neurons alters ER and cytosolic $\mathrm{Ca}^{2+}$ dynamics as well as BK channel physiology resulting in a hyperexcitable state and a painful 
phenotype. That said, how PERK activation in EAE/MS exactly influences the expression of BK channels and auxiliary subunits remains to be determined.

The majority of cellular $\mathrm{Ca}^{2+}$ is stored in the ER and is tightly regulated by ER-Ca ${ }^{2+}$ transporters namely sarco/endoplasmic reticulum $\mathrm{Ca}^{2+}$-ATPase (SERCA), inositol triphosphate receptors (IP3R), and ryanodine receptors (RyR). Caffeine is known to sensitize RyRs to very low concentrations of cytosolic $\mathrm{Ca}^{2+}$ which in turn releases $\mathrm{ER} \mathrm{Ca}^{2+}$ into the cytosol (50). Since caffeine stimulation depletes $\mathrm{ER} \mathrm{Ca}^{2+}$ stores, we used caffeine-induced $\mathrm{Ca}^{2+}$ transients to examine the levels of luminal $\mathrm{Ca}^{2+}$ in the ER. The exact effect of increased ER luminal $\mathrm{Ca}^{2+}$ on neuronal function is difficult to predict primarily because $\mathrm{Ca}^{2+}$ plays such a varied role inside the cell (50). However, aberrant $\mathrm{Ca}^{2+}$ dynamics have been closely linked to painful phenotypes (51, 52). We found small diameter sensory neurons in EAE to have increased CICR and $\mathrm{KCl}$ mediated cytosolic $\mathrm{Ca}^{2+}$ transients. In vitro application of 4-PBA and AMG44 on dissociated DRG neurons from EAE animals reduced the sensitivity to caffeine and $\mathrm{KCl}$ stimulation suggesting that these drugs restore $\mathrm{Ca}^{2+}$ homeostasis of small diameter sensory neurons.

BK channels act as "coincidence detectors", consolidating both cytosolic $\mathrm{Ca}^{2+}$ levels and membrane potential, both of which are important factors in initiating and maintaining sensitization (53). To this effect, a reduction in BK channel current in the DRG is also associated with nerve injury $(54,55)$ and inflammation-induced pain $(56-58)$. In this study, we found paxilline-sensitive BK channel currents almost exclusively in IB4+ sensory neurons (Fig. 9) similar to what has previously been reported (34). BK channels may be spatially coupled to voltage-gated $\mathrm{Ca}^{2+}$ channels and ryanodine receptors allowing even small increases in cytosolic $\mathrm{Ca}^{2+}$ to immediately influence the excitability of the cell $(59,60)$. Moreover, reduced BK channel activity, as observed in this study, has been implicated in increased neurotransmission 
$(53,61)$, hyperexcitability (34) and a more depolarized resting membrane potential (62).

Behaviourally, sensory neuron specific (SNS) knockout of the pore-forming BK $\alpha$ subunit enhanced chronic inflammatory pain while a BK channel opener, NS1619, dampened inflammation-induced pain behaviours, suggesting that BK channels inhibit sensory input in inflammatory states (58). In this regard, we observe a loss of $\mathrm{BK} \alpha$ subunit mRNA expression in the DRG of EAE mice (Fig. 10-1). However, 4-PBA and AMG44 treatment of EAE sensory neurons in vitro did not reverse this loss, implying that ER stress mechanisms may affect other modulatory subunits of BK channels in this disease.

The auxiliary subunits of BK channels modulate the channel's $\mathrm{Ca}^{2+}$ and voltage sensitivity, ultimately modulating the cell's firing properties $(53,60)$. In particular, the $\beta 4$ subunit slows activation and deactivation kinetics of the BK channel as well as reducing $\mathrm{Ca}^{2+}$ sensitivity of the channel at low intracellular $\mathrm{Ca}^{2+}$ levels while increasing $\mathrm{Ca}^{2+}$ sensitivity at high intracellular $\mathrm{Ca}^{2+}$ concentrations (63). Knockout of the $\beta 4$ subunit in hippocampal dentate gyrus granule cells increased fast afterhyperpolarization amplitude and spike frequency of the cell (60). Loss of $\beta 4$ subunits is further correlated with seizure activity and heterozygous $\beta 4$ knockout mice are particularly prone to kainic acid induced seizures (64). Of note, increased neuronal activity is also postulated to reduce levels of $\beta 4$ subunits in an activity-dependent manner (64). As such, we observed a loss of $\beta 4$ mRNA expression in the DRG of EAE mice, corresponding to a depolarizing shift in the $\mathrm{V}_{1 / 2}$ of $\mathrm{BK}$ channels in IB4+ neurons and the onset of pain hypersensitivity in our model. In vitro, 4-PBA and AMG44 treatment on EAE neurons increased the expression of Kcnmb4 and normalized BK channel properties. Interestingly, $\beta 4$ mRNA was also reduced in the DRGs of MS patients further suggesting that BK channel physiology may be 
affected in MS. Hence, alleviation of ER stress may ameliorate pain in MS by normalizing BK channel physiology.

Current approaches to treat pain in MS generally involves NSAIDs, opioids, antidepressants, and antiepileptics. However, these treatment avenues often offer minimal relief and accompany a host of undesired side-effects $(3,65)$. Since BK channels are ubiquitously expressed in a variety of tissues, including the circulatory system, pharmacologically targeting BK channels directly may also result in severe side-effects (66). In contrast, ER stress modulators like 4-PBA and AMG44 can alleviate ER stress and normalize BK channel properties, ameliorating pain and limiting the chances for adverse side-effects (Fig. 11A, B). 


\section{A}

Figure 11
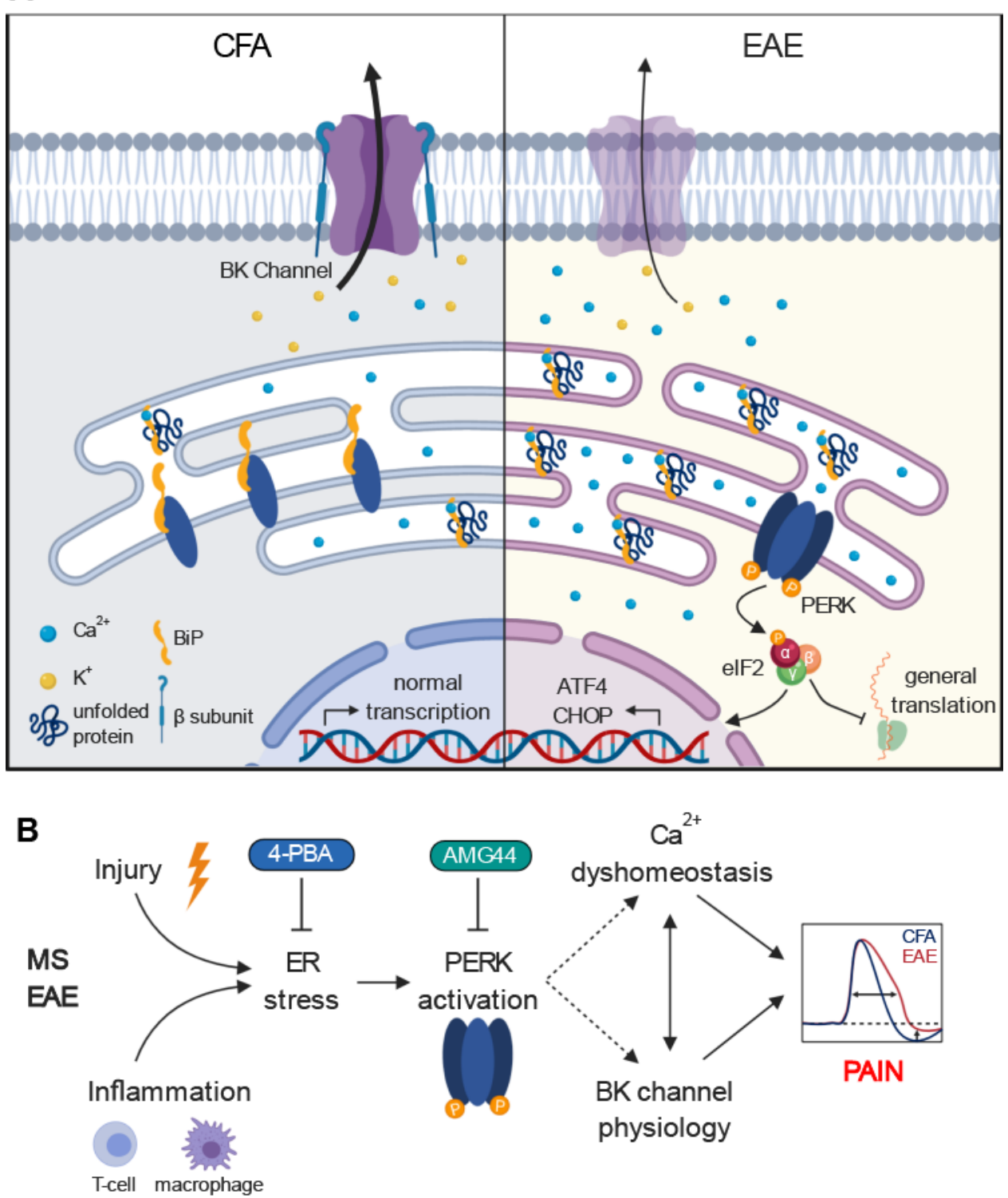

Figure 11. Proposed mechanism (E, F) Sensory neurons, particularly IB4+ nociceptors, from EAE experience ER stress and consequent activation of the PERK-eIF2 $\alpha$ pathway. Subsequent modulation of BK channel physiology and ER-Ca ${ }^{2+}$ dyshomeostasis ultimately contributes to pain hypersensitivity in EAE mice. 4-PBA and AMG44 reduce ER stress and PERK phosphorylation, respectively, to normalize $\mathrm{Ca}^{2+}$ homeostasis, $\mathrm{BK}$ channel physiology, and alleviate pain. 


\section{Author Contributions}

M.S.Y., H.T.K., T.S., B.J.K. was involved in designing the research study. M.S.Y, S.S., S.M.L., T.F., A.C., K.T., M.D., G.T. conducted experiments and analysed data. G.J.S. processed and provided human samples. K.B. provided reagents and equipment. M.S.Y. and B.J.K. composed the manuscript. B.J.K. supervised the study. 


\section{References}

1. Drulovic J et al. The Prevalence of Pain in Adults with Multiple Sclerosis: A Multicenter Cross-Sectional Survey. [Internet]. Pain Med. 2015;16(8):1597-602.

2. Solaro $\mathrm{C}$ et al. Identifying neuropathic pain in patients with multiple sclerosis: a crosssectional multicenter study using highly specific criteria. [Internet]. J. Neurol. 2018;265(4):828835.

3. Hadjimichael O, Kerns RD, Rizzo MA, Cutter G, Vollmer T. Persistent pain and uncomfortable sensations in persons with multiple sclerosis. [Internet]. Pain 2007;127(1-2):3541.

4. Waxman SG, Zamponi GW. Regulating excitability of peripheral afferents: emerging ion channel targets. [Internet]. Nat. Neurosci. 2014;17(2):153-63.

5. Chung JM, Chung K. Importance of Hyperexcitability of DRG Neurons in Neuropathic Pain. Pain Pract. 2002;2(2):87-97.

6. Latremoliere A, Woolf CJ. Central sensitization: a generator of pain hypersensitivity by central neural plasticity. [Internet]. J. Pain 2009;10(9):895-926.

7. Khan N, Smith MT. Multiple sclerosis-induced neuropathic pain: pharmacological management and pathophysiological insights from rodent EAE models. Inflammopharmacology 2014;22(1):1-22.

8. Thorburn KC, Paylor JW, Webber CA, Winship IR, Kerr BJ. Facial hypersensitivity and trigeminal pathology in mice with experimental autoimmune encephalomyelitis. [Internet]. Pain 2016;157(3):627-42.

9. Yousuf MS, Zubkow K, Tenorio G, Kerr B. The chloride co-transporters, NKCC1 and KCC2, in experimental autoimmune encephalomyelitis (EAE). Neuroscience 2017;344.

doi:10.1016/j.neuroscience.2016.12.046

10. Yousuf MS et al. Sensory Neurons of the Dorsal Root Ganglia Become Hyperexcitable in a T-Cell-Mediated MOG-EAE Model of Multiple Sclerosis. eneuro [published online ahead of print: 2019]; doi:10.1523/eneuro.0024-19.2019

11. Mifflin KA et al. Voluntary wheel running reveals sex-specific nociceptive factors in murine experimental autoimmune encephalomyelitis. Pain [published online ahead of print: 2019]; doi:10.1097/j.pain.0000000000001465

12. Duffy SS et al. Peripheral and Central Neuroinflammatory Changes and Pain Behaviors in an Animal Model of Multiple Sclerosis. [Internet]. Front. Immunol. 2016;7:369.

13. Frezel N, Sohet F, Daneman R, Basbaum AI, Braz JM. Peripheral and central neuronal ATF3 precedes CD4+ T-cell infiltration in EAE. [Internet]. Exp. Neurol. 2016;283(Pt A):224-234.

14. Lu J et al. Pain in experimental autoimmune encephalitis: a comparative study between different mouse models [Internet]. J Neuroinflammation 2012;9(1):233.

15. Stone $\mathrm{S}$, Lin W. The unfolded protein response in multiple sclerosis. [Internet]. Front. Neurosci. 2015;9:264.

16. Hetz C, Mollereau B. Disturbance of endoplasmic reticulum proteostasis in neurodegenerative diseases. [Internet]. Nat. Rev. Neurosci. 2014;15(4):233-49.

17. Sano R, Reed JC. ER stress-induced cell death mechanisms. [Internet]. Biochim. Biophys. Acta 2013;1833(12):3460-3470.

18. Inceoglu B et al. Endoplasmic reticulum stress in the peripheral nervous system is a significant driver of neuropathic pain. [Internet]. Proc. Natl. Acad. Sci. U. S. A. 
2015;112(29):9082-7.

19. Khoutorsky A et al. eIF2 $\alpha$ phosphorylation controls thermal nociception.. Proc. Natl. Acad. Sci. U. S. A. 2016;113(42):11949-11954.

20. Kong D et al. Tanshinone II A Affects Diabetic Peripheral Neuropathic Pain via Spinal Dorsal Horn Neuronal Circuitry by Modulating Endoplasmic Reticulum Stress Pathways. [Internet]. Exp. Clin. Endocrinol. Diabetes [published online ahead of print: July 11, 2019]; doi:10.1055/a-0919-4614

21. Chopra $\mathrm{S}$ et al. IRE1 $\alpha$-XBP1 signaling in leukocytes controls prostaglandin biosynthesis and pain. [Internet]. Science 2019;365(6450). doi:10.1126/science.aau6499

22. Chen $\mathrm{C}-\mathrm{H}$ et al. 4-Phenylbutyric acid protects against vasculitic peripheral neuropathy induced by ischaemia-reperfusion through attenuating endoplasmic reticulum stress. [Internet]. Inflammopharmacology 2019;27(4):713-722.

23. Pan P-T et al. Resveratrol alleviates nuclear factor- $\kappa \mathrm{B}-$ mediated neuroinflammation in vasculitic peripheral neuropathy induced by ischaemia-reperfusion via suppressing endoplasmic reticulum stress. [Internet]. Clin. Exp. Pharmacol. Physiol. 2019;46(8):770-779.

24. Yamaguchi Y et al. Endoplasmic Reticulum Stress in the Dorsal Root Ganglion Contributes to the Development of Pain Hypersensitivity after Nerve Injury. [Internet]. Neuroscience 2018;394:288-299.

25. Gavini CK et al. Liver X Receptors Protect Dorsal Root Ganglia from Obesity-Induced Endoplasmic Reticulum Stress and Mechanical Allodynia. [Internet]. Cell Rep. 2018;25(2):271277.e4.

26. Benson CA, Kerr BJ. Pain and Cognition in Multiple Sclerosis. Curr Top Behav Neurosci 2014;20:201-215.

27. Schenk GJ et al. Roles for HB-EGF and CD9 in multiple sclerosis. [Internet]. Glia 2013;61(11):1890-905.

28. Olechowski CJ, Tenorio G, Sauve Y, Kerr BJ. Changes in nociceptive sensitivity and object recognition in experimental autoimmune encephalomyelitis (EAE). Exp Neurol 2013;241:113121.

29. Vidal RL, Hetz C. Unspliced XBP1 controls autophagy through FoxO1 [Internet]. Cell Res. 2013;23(4):463-464.

30. Ayala $\mathrm{P}$ et al. Attenuation of endoplasmic reticulum stress using the chemical chaperone 4phenylbutyric acid prevents cardiac fibrosis induced by isoproterenol. [Internet]. Exp. Mol. Pathol. 2012;92(1):97-104.

31. Olechowski CJ et al. A diminished response to formalin stimulation reveals a role for the glutamate transporters in the altered pain sensitivity of mice with experimental autoimmune encephalomyelitis (EAE). [Internet]. Pain 2010;149(3):565-72.

32. Kaur B et al. Proteomic profile of 4-PBA treated human neuronal cells during ER stress. [Internet]. Mol. Omi. 2018;14(1):53-63.

33. Smith AL et al. Discovery of 1H-pyrazol-3(2H)-ones as potent and selective inhibitors of protein kinase R-like endoplasmic reticulum kinase (PERK). [Internet]. J. Med. Chem. 2015;58(3):1426-41.

34. Zhang XL, Mok LP, Katz EJ, Gold MS. BKCa currents are enriched in a subpopulation of adult rat cutaneous nociceptive dorsal root ganglion neurons. Eur. J. Neurosci. [published online ahead of print: 2010]; doi:10.1111/j.1460-9568.2009.07060.x

35. Usoskin D et al. Unbiased classification of sensory neuron types by large-scale single-cell 
RNA sequencing. [Internet]. Nat. Neurosci. 2015;18(1):145-53.

36. Barragán-Iglesias $\mathrm{P}$ et al. Activation of the integrated stress response in nociceptors drives methylglyoxal-induced pain. [Internet]. Pain 2019;160(1):160-171.

37. Zhang E et al. Endoplasmic reticulum stress impairment in the spinal dorsal horn of a neuropathic pain model. [Internet]. Sci. Rep. 2015;5:11555.

38. Yang ES et al. Involvement of endoplasmic reticulum stress response in orofacial inflammatory pain. [Internet]. Exp. Neurobiol. 2014;23(4):372-80.

39. Andhavarapu S, Mubariz F, Arvas M, Bever C, Makar TK. Interplay between ER stress and autophagy: A possible mechanism in multiple sclerosis pathology. [Internet]. Exp. Mol. Pathol. 2019;108:183-190.

40. Yue Y, Stanojlovic M, Lin Y, Karsenty G, Lin W. Oligodendrocyte-specific ATF4 inactivation does not influence the development of EAE. [Internet]. J. Neuroinflammation 2019;16(1):23.

41. Stone $\mathrm{S}$ et al. Activating transcription factor $6 \alpha$ deficiency exacerbates oligodendrocyte death and myelin damage in immune-mediated demyelinating diseases. [Internet]. Glia 2018;66(7):1331-1345.

42. Lin W et al. Oligodendrocyte-specific activation of PERK signaling protects mice against experimental autoimmune encephalomyelitis. [Internet]. J. Neurosci. 2013;33(14):5980-91. 43. Kolb PS et al. The therapeutic effects of 4-phenylbutyric acid in maintaining proteostasis. [Internet]. Int. J. Biochem. Cell Biol. 2015;61:45-52.

44. Dasgupta S, Zhou Y, Jana M, Banik NL, Pahan K. Sodium phenylacetate inhibits adoptive transfer of experimental allergic encephalomyelitis in SJL/J mice at multiple steps. [Internet]. $J$. Immunol. 2003;170(7):3874-82.

45. Hussien Y, Cavener DR, Popko B. Genetic inactivation of PERK signaling in mouse oligodendrocytes: normal developmental myelination with increased susceptibility to inflammatory demyelination. [Internet]. Glia 2014;62(5):680-91.

46. Lin $\mathrm{W}$ et al. The integrated stress response prevents demyelination by protecting oligodendrocytes against immune-mediated damage. [Internet]. J. Clin. Invest. 2007;117(2):44856.

47. Pakos-Zebrucka $\mathrm{K}$ et al. The integrated stress response. [Internet]. EMBO Rep. 2016;17(10):1374-1395.

48. Khoutorsky A, Price TJ. Translational Control Mechanisms in Persistent Pain [Internet]. 2018:

49. Hetz C, Axten JM, Patterson JB. Pharmacological targeting of the unfolded protein response for disease intervention. [Internet]. Nat. Chem. Biol. 2019;15(8):764-775.

50. Verkhratsky A. Physiology and pathophysiology of the calcium store in the endoplasmic reticulum of neurons. [Internet]. Physiol. Rev. 2005;85(1):201-79.

51. Hagenston AM, Simonetti M. Neuronal calcium signaling in chronic pain. Cell Tissue Res. 2014;357(2):407-426.

52. Bourinet E et al. Calcium-permeable ion channels in pain signaling. [Internet]. Physiol. Rev. 2014;94(1):81-140.

53. Contet C, Goulding SPP, Kuljis DAA, Barth ALL. BK Channels in the Central Nervous System [Internet]. In: International Review of Neurobiology. Academic Press Inc.; 2016:281342

54. Chen S-R, Cai Y-Q, Pan H-L. Plasticity and emerging role of BKCa channels in nociceptive 
control in neuropathic pain. [Internet]. J. Neurochem. 2009;110(1):352-62.

55. Cao X-H, Chen S-R, Li L, Pan H-L. Nerve injury increases brain-derived neurotrophic factor levels to suppress BK channel activity in primary sensory neurons. [Internet]. J. Neurochem. 2012;121(6):944-53.

56. Zhang XL, Mok LP, Lee KY, Charbonnet M, Gold MS. Inflammation-induced changes in $\mathrm{BK}(\mathrm{Ca})$ currents in cutaneous dorsal root ganglion neurons from the adult rat. [Internet]. Mol. Pain 2012;8:37.

57 . Berta $T$ et al. Extracellular caspase- 6 drives murine inflammatory pain via microglial TNF- $\alpha$ secretion. J. Clin. Invest. 2014;124(3):1173-1186.

58. Lu R et al. BKCa channels expressed in sensory neurons modulate inflammatory pain in mice. [Internet]. Pain 2014;155(3):556-65.

59. Irie T, Trussell LO. Double-Nanodomain Coupling of Calcium Channels, Ryanodine Receptors, and BK Channels Controls the Generation of Burst Firing. [Internet]. Neuron 2017;96(4):856-870.e4.

60. Wang B et al. Knockout of the BK $\beta 4$-subunit promotes a functional coupling of BK channels and ryanodine receptors that mediate a fAHP-induced increase in excitability. [Internet]. J. Neurophysiol. 2016;116(2):456-65.

61. Griguoli M, Sgritta M, Cherubini E. Presynaptic BK channels control transmitter release: physiological relevance and potential therapeutic implications. [Internet]. J. Physiol. 2016;594(13):3489-500.

62. Sun X, Hirano AA, Brecha NC, Barnes S. Calcium-activated BKCa channels govern dynamic membrane depolarizations of horizontal cells in rodent retina. J. Physiol. 2017;595(13):4449-4465.

63. Behrens R et al. hKCNMB3 and hKCNMB4, cloning and characterization of two members of the large-conductance calcium-activated potassium channel $\beta$ subunit family [Internet]. FEBS Lett. 2000;474(1):99-106.

64. Whitmire LE et al. Downregulation of KCNMB4 expression and changes in BK channel subtype in hippocampal granule neurons following seizure activity. PLoS One 2017;12(11). doi:10.1371/journal.pone.0188064

65. Urits I et al. Advances in the Understanding and Management of Chronic Pain in Multiple Sclerosis: a Comprehensive Review. [Internet]. Curr. Pain Headache Rep. 2019;23(8):59. 66. Kshatri AS, Gonzalez-Hernandez A, Giraldez T. Physiological Roles and Therapeutic Potential of $\mathrm{Ca} 2+$ Activated Potassium Channels in the Nervous System [Internet]. Front. Mol. Neurosci. 2018;11. doi:10.3389/fnmol.2018.00258 


\section{Extended Figures}

Figure 6-1
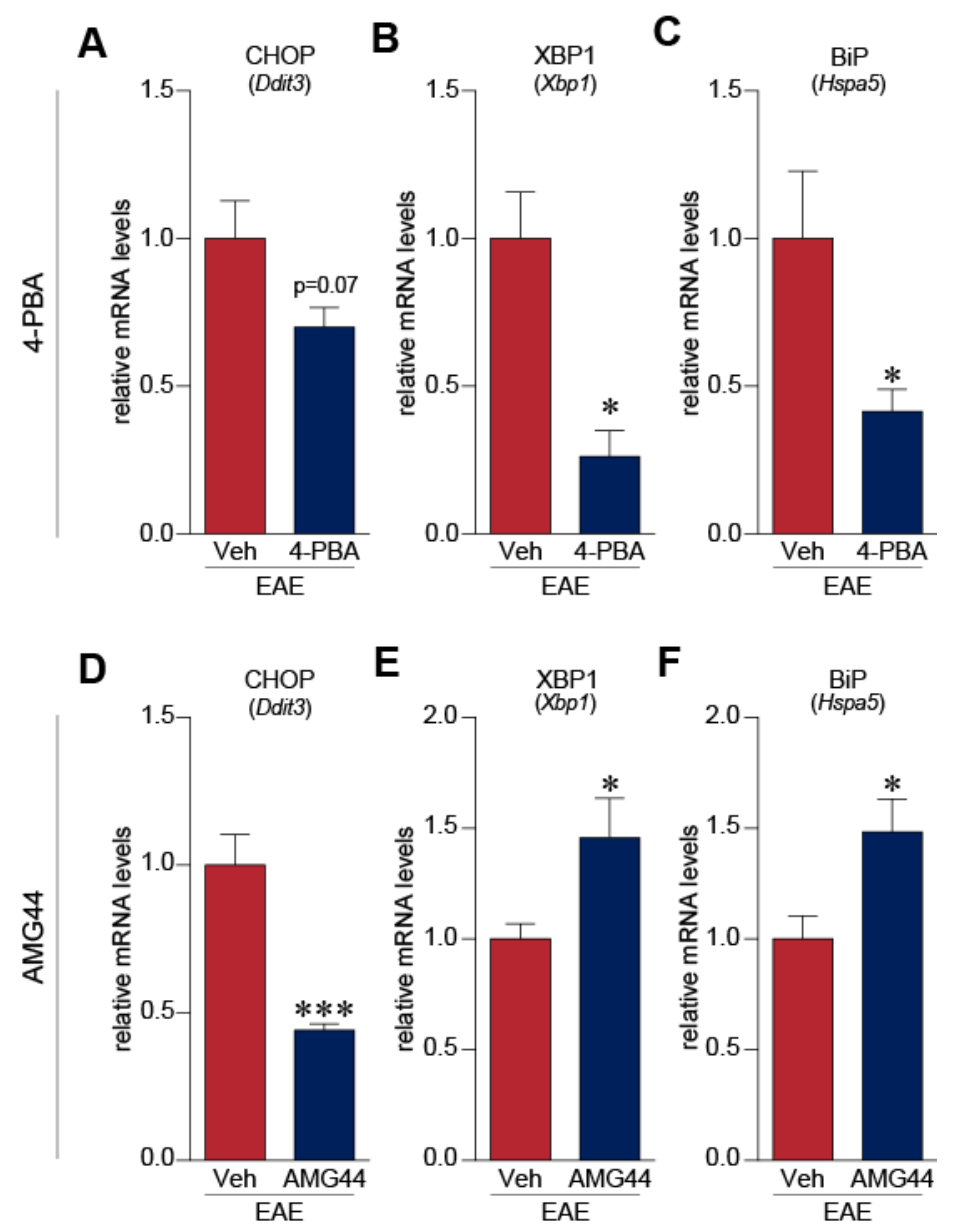

Figure 6-1. 4-PBA and AMG44 treatment, in vitro, alters gene expression of UPRassociated transcripts. $(\mathrm{A}, \mathrm{B}, \mathrm{C})$ 4-PBA treatment $(\mathrm{n}=4)$ in EAE cells reduced expression of $\mathrm{XBP1}$, and BiP mRNA expression as compared to vehicle (HBSS) treated EAE neurons $(\mathrm{n}=4)$. CHOP expression trended towards a reduction with 4-PBA treatment. (D, E, F) AMG44 (n=5) significantly dampened the mRNA levels of CHOP, as intended, in dissociated DRG neurons from EAE animals. However, AMG44 treatment elevated XBP1 and BiP transcripts as compared to vehicle $\left(0.01 \%\right.$ DMSO) treated EAE neurons $(\mathrm{n}=5) .{ }^{*} \mathrm{p}<0.05, * * * \mathrm{p}<0.001$, unpaired t-test. 
Figure 10-1
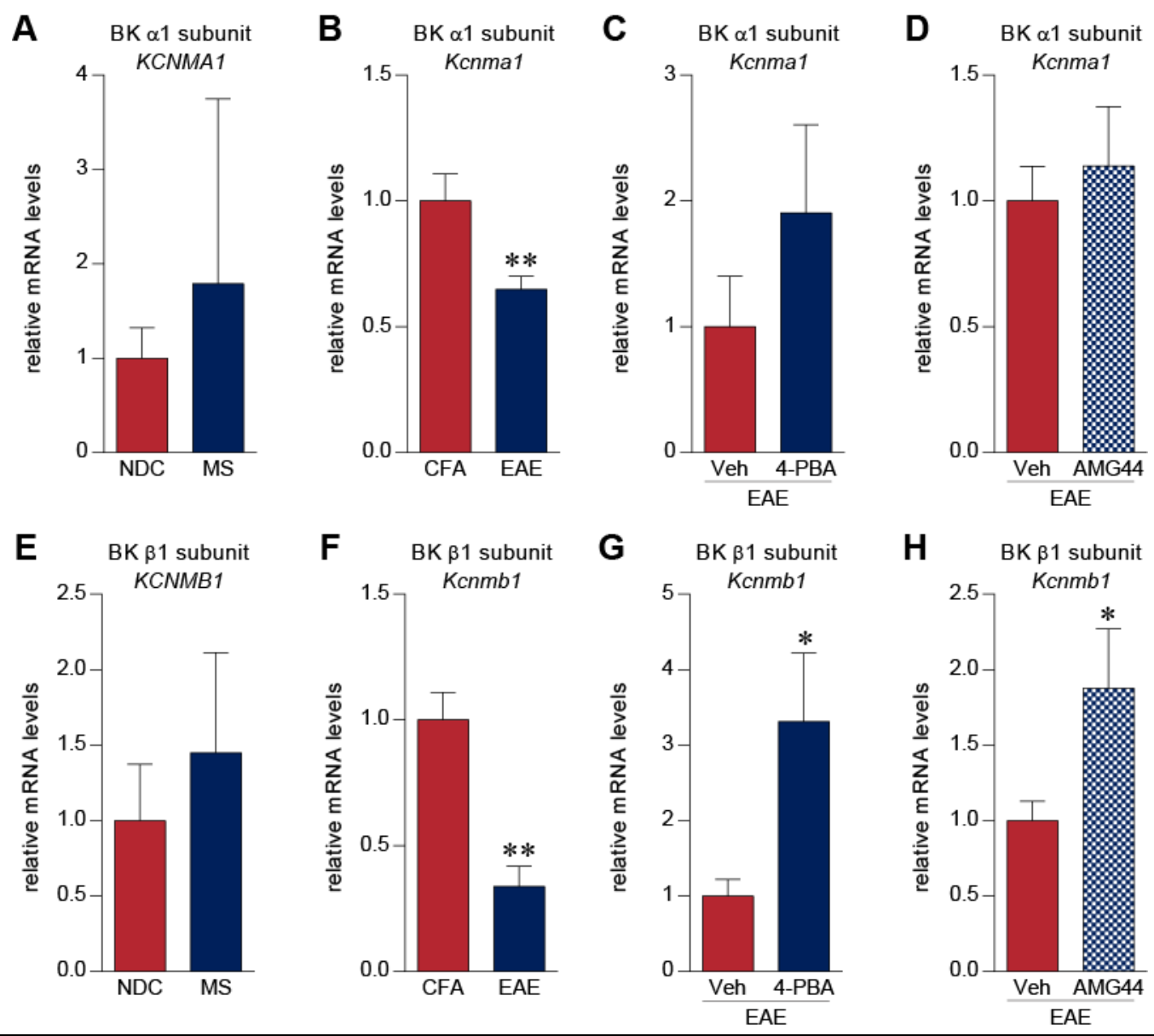

Figure 10-1. EAE alters BK channel $\alpha 1$ and $\beta 1$ subunit expression. (A, E) BK $\alpha 1$ and $\beta 1$ subunit mRNA expression was not altered in MS DRGs $(n=8)$ as compared to NDCs $(n=5)$. (B, F) On the contrary, EAE DRGs ( $\mathrm{n}=7$ ) showed a significant reduction of Kcnmal and Kcnmb1 transcripts compared to DRGs from CFA control animals $(n=4)$. (C, D, G, H) 4-PBA $(n=4)$ and AMG44 ( $\mathrm{n}=5)$ treatment in vitro elevated levels of Kcnmb1 transcripts while having negligible effects on BK $\alpha 1$ levels. ${ }^{*} \mathrm{p}<0.05,{ }^{*} * \mathrm{p}<0.01$, unpaired t-test. 


\section{Tables}

Table 1-1. Demographics of MS patients and non-demented controls.

\begin{tabular}{|c|c|c|c|c|c|c|c|c|}
\hline $\begin{array}{c}\text { Patient } \\
\text { ID }\end{array}$ & Sex & Age & $\begin{array}{c}\text { Post-mortem } \\
\text { delay } \\
\text { (hh:mm) }\end{array}$ & $\begin{array}{c}\text { Disease } \\
\text { subtype }\end{array}$ & $\begin{array}{c}\text { Chronic } \\
\text { pain }\end{array}$ & $\begin{array}{c}\text { Spinal } \\
\text { lesion }\end{array}$ & $\begin{array}{c}\text { MS } \\
\text { duration } \\
\text { (years) }\end{array}$ & $\begin{array}{c}\text { Cause of } \\
\text { death }\end{array}$ \\
\hline S02 & F & 85 & $6: 25$ & NDC & Y & N & - & Euthanasia* \\
\hline S05 & F & 78 & $7: 10$ & NDC & Y & N & - & Euthanasia \\
\hline S07 & F & 60 & $8: 10$ & NDC & Y & N & - & Cancer \\
\hline S11 & F & 95 & $7: 05$ & NDC & N & N & - & Sepsis \\
\hline S15 & F & 75 & $9: 10$ & NDC & Y & N & - & Euthanasia \\
\hline S19 & F & 88 & $6: 20$ & NDC & N & N & - & Euthanasia \\
\hline S20 & F & 60 & $5: 30$ & NDC & Y & N & - & Euthanasia \\
\hline S01 & F & 65 & $10: 45$ & SPMS & Y & Y & 16 & CVA \\
\hline S04 & F & 56 & $10: 30$ & SPMS & N & Y & 21 & Euthanasia \\
\hline S06 & F & 35 & $10: 20$ & SPMS & N & N & 10 & Euthanasia \\
\hline S08 & F & 61 & $10: 00$ & SPMS & Y & Y & 2 & Euthanasia \\
\hline S09 & F & 74 & $7: 50$ & SPMS & Y & Y & 50 & Euthanasia \\
\hline S10 & F & 57 & $10: 40$ & SPMS & Y & Y & 25 & Euthanasia \\
\hline S13 & F & 50 & $9: 05$ & SPMS & Y & Y & 12 & Euthanasia \\
\hline S17 & F & 66 & $9: 45$ & PPMS & Y & Y & 23 & Pneumonia \\
\hline S18 & F & 73 & $7: 05$ & PPMS & Y & N/A & 30 & Euthanasia \\
\hline
\end{tabular}

*Euthanasia was typically performed with barbiturate (thiopental, pentobarbital) overdose coupled with a muscle relaxant (rocuronium bromide). ${ }^{\$}$ Metastasized mammacarcinoma. CVA: Cardiovascular accident, SPMS: Secondary progressive MS, PPMS: Primary progressive MS, NDC: Non-demented control 
Table 2-1. Antibodies used in this study.

\begin{tabular}{|c|c|c|c|}
\hline Antibody & Host & Source & Dilution Factor \\
\hline $\mathrm{BiP}$ & Ms & BD Biosciences, 610979 & $1: 1,000(\mathrm{WB})$ \\
\hline $\mathrm{BiP}$ & $\mathrm{Rb}$ & Novus, NBP1-06274 & $\begin{array}{c}1: 2,000(\mathrm{WB}) \\
1: 200(\mathrm{IHC})\end{array}$ \\
\hline $\mathrm{CHOP}$ & Ms & Enzo Life Sciences, ALX-804-551-C100 & $1: 1,000$ \\
\hline XBP1 & $\mathrm{Rb}$ & Abcam, ab37152 & $\begin{array}{c}1: 1,000(\mathrm{WB}) \\
1: 200(\mathrm{IHC})\end{array}$ \\
\hline $\mathrm{eIF} 2 \alpha$ & $\mathrm{Rb}$ & Cell Signaling, 9722 & $1: 1,000$ \\
\hline p-eIF2 $\alpha($ Ser51) & $\mathrm{Rb}$ & Cell Signaling, 3597 & $1: 1,000$ \\
\hline PERK & $\mathrm{Rb}$ & Cell Signaling, 3192 & $1: 1,000$ \\
\hline p-PERK (Thr980) & $\mathrm{Rb}$ & Cell Signaling, 3179 & $1: 500$ \\
\hline Iba1 & $\mathrm{Rb}$ & Wako, 019-19741 & $1: 500$ \\
\hline CD4 & Rt & BioRad, MCA2691 & $1: 200$ \\
\hline $\mathrm{cFOS}$ & $\mathrm{Rb}$ & Cell Signalling, 2250 & $1: 1,000$ \\
\hline CD88 (or C5aR1) & Rt & BioRad, MCA2456 & $1: 200$ \\
\hline CD3 & Rt & BioRad, MCA1477 & $1: 200$ \\
\hline NFH & $\mathrm{Ck}$ & ThermoFisher, PA1-10002 & $1: 5,000$ \\
\hline IB4-AF488 & - & ThermoFisher, I21411 & $1: 100$ \\
\hline Goat anti-Mouse IgG, AF750 & Gt & Abcam, ab175733 & $1: 10,000$ \\
\hline Goat anti-Rabbit IgG, AF680 & Gt & ThermoFisher, A21057 & $1: 10,000$ \\
\hline Goat anti-Chicken IgG AF594 & Gt & ThermoFisher, A11042 & $1: 200$ \\
\hline Goat anti-Rabbit IgG AF488 & Gt & ThermoFisher, A11008 & $1: 200$ \\
\hline Goat anti-Rat IgG AF594 & Gt & ThermoFisher, A11007 & $1: 200$ \\
\hline Goat anti-Rabbit IgG HRP & Gt & Jackson Laboratories, 111-035-144 & $1: 10,000$ \\
\hline
\end{tabular}

